\title{
Transverse cracking in the bulk and at the free edge of thin-ply composites : experiments and multiscale modelling
}

\author{
S. Kohler, J. Cugnoni*, R. Amacher, J. Botsis \\ École Polytechnique Fédérale de Lausanne (EPFL), LMAF-IGM-STI, Station No 9, \\ CH-1015 Lausanne, Switzerland
}

\begin{abstract}
Thin-ply composites were shown to exhibit significantly delayed transverse cracking, but the linear onset of damage scaling with ply thickness reported by Amacher et al. [1] did not correspond to the established LEFM based in-situ strength model. This study further investigates this experimental behaviour by simultaneously comparing in-situ free edge crack observation with acoustic emission measurements as well as performing ex-situ X-ray tomography observations of crack propagation. A multi-scale FE model was used to better understand the damage mechanisms at play, and showed a decreasing trend of the apparent toughness with decreasing ply thickness, which explains the deviation from the existing model. Transverse cracking at the free edges was observed to propagate quickly towards the center of the specimens for the thickest plies, while in the thinnest plies it is significantly delayed, up to a point where no cracks can reach the center of the sample before final failure.
\end{abstract}

Keywords: A. Carbon fibres, B. Mechanical properties, C. Finite element analysis, D. Mechanical testing

\footnotetext{
*. Corresponding author

Email address: joel.cugnoni@epfl.ch (J. Cugnoni)
} 


\section{Introduction}

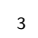

4

5

6

Ply thickness effects in fibre reinforced polymers were documented very early on with the work of Parvizi et al. [2], but became a topic of renewed interest in the last 10 years due to advances in manufacturing techniques allowing the production of prepreg tapes down to a ply thickness of less than $20 \mu \mathrm{m}$. Besides the much increased design space offered by these materials, as well as the significantly improved mechanical properties, the notable increase in transverse tensile strength with decreased ply thickness $t$ was one of the most striking feature of these new materials, and naturally drew a lot of attention to their experimental characterization.

Sihn et al. [3] performed unnotched tensile tests on quasi-isotropic specimens of either $40 \mu \mathrm{m}$ or $200 \mu \mathrm{m}$ ply thickness, with the thicker ones obtained by sublaminate or ply-block stacking of 5 of the thinnest ones. They noticed a strength improvement for the specimens produced with the sub-laminate stacking sequence. They also recorded an improved fatigue life in both unnotched and open hole tensile tests, and reduced delamination as well as increased compression after impact resistance for the specimens produced with the thinner plies. Wisnom et al. [4] performed tensile tests of unidirectional and quasi-isotropic specimens of varying sample and ply thickness. If a small increase in strength was noted when increasing the thickness of quasi-isotropic specimens by sub-laminate stacking, a much larger effect was observed when varying the ply thickness by ply-block stacking, accompanied by a change in failure mechanism from fibre failure after partial delamination with the thinner ply-blocks (250 $\mu \mathrm{m}$ or less) to delamination only with the thicker ones $(500 \mu \mathrm{m}$ or more). In an other study, the transverse crack propagation in $90^{\circ}$ layers of different thickness embedded between $0^{\circ}$ plies was studied by Saito et al. [5], who reported the existence of a transverse crack suppression effect for the thinner plies, and related it numerically to a decrease in energy release rate at the crack tip with decreasing ply thickness. The fibre-matrix debonding would appear at similar strains, but their coalescence into formed transverse cracks and their propagation through 
the thickness of the ply were delayed with thinner plies. They also related the higher crack density observed in the thinner plies at high strains to the reduced stress relaxation obtained with smaller transverse cracks. Similar observations regarding the crack density as well as a dependency to the adjacent ply stiffness were reported by Sebaey et al. [6], though on relatively thick plies ( $\geq 183 \mu \mathrm{m})$, by using an in-situ optical observation of the tested specimens' polished free edges. Yokozeki et al. [7] also reported a retardation of matrix cracking accumulation in specimens made of thinner plies coupled with a decreased crack density in the bulk of their samples when observing them by means of x-ray radiographs. Amacher et al. [1] reported both an increase in ultimate strength when decreasing the ply thickness of quasi-isotropic tensile specimens of constant dimensions, as well as an increased onset of damage determined by acoustic emission.

The numerical modelling of such phenomenon has already been worked on, with Canal et al. [8] subjecting an RVE of 30 fibres in random homogeneous dispersion with periodic boundary conditions to transverse tension and out-ofplane shear. This work was carried out by studying an embedded cell using the actual microstructure of a notched beam sample, tested in three-point bending, to study the intraply fracture of fibre-reinforced composite, obtaining an accurate prediction of the material's macroscopic behaviour [9]. Arteiro et al. [10] used an advanced elasto-plastic model including damage for the matrix in which $90^{\circ}$ orthotropic fibres were distributed in a statistically equivalent distribution to a real one. The RVE thus defined was embedded between two $\pm \theta^{\circ}$ layers and the thickness of the micro-modelled zone varied to study the ply thickness effect on the in-situ strength. This model was shown to capture the increase of stress required to grow a crack with decreasing ply thickness. A critical review of this approach compared to experiments and analytical modelling was also published [11].

Before the beginning of the numerical modelling effort in this field, an analytical model was proposed by Camanho et al. [12] based on the previous work of 
Dvorak and Laws [13], where the concept of the in-situ strength of a (constrained) ply as a function of ply thickness was developed. This model was validated against reported observations of the transverse cracking at the free edge of some samples. The onset of damage scaling reported more recently [1] where an acoustic emission cumulative energy threshold was used to define the onset of damage did however deviate from this model, especially for very thin plies, showing a linear scaling consistent with some numerical results of Arteiro et al. [10]. This raised the questions of whether or not the cracks visible at the edge of the specimens could be used as reliable damage indicator for very thin plies, and of what kind of damage mechanism was reflected by the acoustic emission measurements.

The goal of this work is therefore to compare simultaneous observation of the damage at the free edge, in the bulk and by recording the acoustic emission activity. To this effect, in-situ observations of the free edge similar to the ones performed by Sebaey et al. [6] are conducted simultaneously with acoustic emission measurements similar to the ones performed by Amacher et al. [1] in order to directly compare the two phenomena. Subsequent cross-sectional micrographies and x-ray tomographic images of selected specimens that were only partially loaded, to study the crack propagation through the width of the sample at different load levels, are also conducted. An embedded cell multi-scale finite element (FE) model is also developed to study the transverse cracking of the $90^{\circ}$ plies. Finally, the experimental data are compared to the results of the FE model which aims to provide an understanding of the transition between damage mechanisms involved in the size effect of transverse cracking. Boundary conditions equivalent to both free edge and bulk locations are developed for comparison with the experimental data. 


\section{Materials and methods}

\subsection{Experimental Study}

The samples used in this study are made of unidirectional prepregs of Toray M40JB carbon fibres and TP80ep epoxy resin supplied by NTPT in 4 different ply thicknesses, namely $\mathrm{t}=30 \mu \mathrm{m}, 75 \mu \mathrm{m}, 150 \mu \mathrm{m}$ and $300 \mu \mathrm{m}$. The samples were therefore similar to the ones used by Amacher et al. [1]. All of the prepregs supplied were made with same fibre and resin batches and were manufactured on the same production line in order to minimise any potential relevant scatter. The stacking sequence used to produce the symmetric, quasi-isotropic laminates is $[45 / 90 /-45 / 0]_{n S}$ where $n$ is varied to ensure a constant laminate thickness of $2.41 \pm 0.1 \mathrm{~mm}$ for all the samples, no matter which ply thickness was used. The composite plates were cured in an autoclave following the supplier's recommended curing cycle (peak of $80^{\circ} \mathrm{C}$ for 8 hours at 3 bar after an initial 2 hour long plateau at $60^{\circ} \mathrm{C}$ and $1^{\circ} \mathrm{C} / \mathrm{mn}$ ramp rates) using a machined aluminium mould to ensure a uniform and constant volume fraction and a good flatness. The produced plates were then cut with a diamond disc saw into $240 \times 24 \mathrm{~mm}$ specimens following the ASTM D3039 standard [14]. One of the free edges of each sample was finally manually polished along its whole length, down to a paper grit size of $3 \mu \mathrm{m}$. Tapered $2 \mathrm{~mm}$ thick $\pm 45^{\circ}$ GFRP tabs were glued at their extremities and an HBM 6/120 LY41 strain gauge was installed in the middle of the gauge length on one of the faces. The proper alignment of the grips was checked on the first sample of each test series accordingly to the standard with a second strain gauge on the opposite side of the sample. The volume fraction of all plates produced was measured between $51,7 \%$ and $57,9 \%$ with a mean value of $55,5 \%$ and a standard deviation of $2,68 \%$. The stress measurements reported here were consequently all normalised to $55 \%$ volume fraction to account for this small discrepancy according to the formula $\sigma=\frac{55 \%}{v f_{n}} \sigma_{n}$, where $\sigma$ is the stress normalised for $55 \%$ volume fraction, $v f_{n}$ the effective volume fraction of each plate and $\sigma_{n}$ the stress actually measured during the experiment. 
At least six samples of each ply thickness were tested in tension following the ASTM D3039 standard [14] whilst recording the damage activity by simultaneously performing acoustic emission measurements, and monitoring the visible crack growth on the polished lateral free edge using a video microscope. The acoustic emission onset of damage was defined as the stress at which the cumulative acoustic energy reaches a $10^{-15} \mathrm{~J}$ threshold, as acquired by a Mistras-2001 measurement equipment, using a $65 \mathrm{~dB}$ minimum acquisition threshold and an appropriate $\Delta T$-front-end filter to reject acoustic activity taking place out of the gauge length [1]. This procedure ensures that the reported values were comparable with prior measurements performed on the same material $[1,15,16]$. The pictures of the polished free edges were recorded using a Guppy Pro F-146 CCD camera mounted on an Olympus SZX12 stereo microscope at 1Hz. This slow acquisition speed coupled with a slower loading speed of $0.125 \mathrm{~mm} / \mathrm{min}$ were required to be able to adjust the focus during the test without significant loss of data. The size of the observation window, always located close to the center of the gauge region, ranged from $1.1 \mathrm{x} 0.8 \mathrm{~mm}$ for the $30 \mu \mathrm{m}$ plies to $3.1 \mathrm{x} 2.3 \mathrm{~mm}$ for the $150 \mu \mathrm{m}$ and $300 \mu \mathrm{m}$ ones, corresponding to an optical magnification ranging from $2.5 \mathrm{x}$ to $6.5 \mathrm{x}$ depending on the ply thickness. The magnification was kept as low as possible for the thicker plies in order to capture as much $90^{\circ}$ ply length as possible whilst ensuring that the cracks remained visible. At the other end of the spectrum, the magnification could not be increased further for the thinnest plies as the resulting depth of field would not allow a proper focus. After testing, the free edges of selected specimens were observed under a higher magnification optical microscope or in SEM to ensure that the limited resolution of the optical equipment used in-situ did not prevent the observation of some smaller damage elements during the tests.

Selected samples were used to study the propagation of the free edge cracks into the width of the sample by means of interrupted tests. The stress levels at which the loading was stopped were chosen following the results presented in section 3.1 to either be representative of a point where free edge cracks were 
present but the onset of damage determined by acoustic emission had not been reached, or of a point where this threshold was reached but the sample had not yet failed. Consequently, one sample made out of $150 \mu \mathrm{m}$ plies was loaded until $0.64 \%$ strain, another one until $0.89 \%$ strain, and a sample made out of $75 \mu \mathrm{m}$ plies loaded to $0.89 \%$ strain at the same loading rate as used during the previous complete tests. It was not possible to obtain a sample made of $75 \mu \mathrm{m}$ plies where the loading exceeded the acoustic emission threshold as it ruptured before the loading was halted. After the desired stress levels were reached, the loading was swiftly interrupted and the sample removed from the testing apparatus. A section of the gauge length close to its center was then cut through the middle of its width as shown on Fig. 1 using a diamond wire saw with a nominal wire diameter of $130 \mu \mathrm{m}$. The cut line revealing the middle of the sample was then polished, and a new set of tabs glued to it. This "partial sample" was finally reloaded in a small screw driven jig to reopen possible cracks, at a loading inferior to $0.1 \%$ strain. This loaded section was then observed under a Keyence VHX 500 microscope at an optical magnification of $15 x$, using a mix of concentric and ring lighting, over a length of approximately $10 \mathrm{~mm}$. The same observation procedure was applied to the original polished free edge of the sample. A reference line drawn across the width of the gauge length before the cut ensured that the observation at the free edge and in the newly revealed bulk could be spatially superimposed for comparison.

A similar interrupted testing procedure was applied on a second set of samples in order to observe the crack propagation through the bulk of the specimens by means of X-ray tomography. An RX-Solutions Ultratom micro CT scanning device was used to reveal the crack presence, where a resolution of approximatively $7 \mu \mathrm{m}$ per voxel allowed the observation of $10 \mathrm{~mm}$ gauge length over half of the width of the sample for each scan. The micro damage detection at this resolution was made possible by the use of a $\mathrm{ZnI}_{2}$-based contrasting penetrant solution which was shown to produce good contrast [17] and has the additional benefit to free the imaging process from time constraints as the iodide 
compounds formed in the solution stay in the sample even after evaporation of the solution. To ensure a good penetration of this contrasting agent, samples were immersed for 24 hours whilst being slightly reloaded (typically $0.065 \%$ strain) to reopen the cracks previously created during the test.

Two samples made of $150 \mu \mathrm{m}$ plies were again loaded until $0.64 \%$ and $0.89 \%$ applied strain, and three samples made of $100 \mu \mathrm{m}$ plies were loaded to $0.64 \%$, $0.83 \%$ and $0.89 \%$ strain. The choice of the $100 \mu \mathrm{m}$ ply thickness over the previously used $75 \mu \mathrm{m}$ ones was solely due to material availability. The goal was to obtain an insight into the bulk damage present at a stress level inferior to the acoustic emission onset threshold, but superior to the onset of free edge cracking. This could then be compared to the damage state in another similar sample loaded at a stress level exceeding the acoustic emission threshold.

A final $100 \mu \mathrm{m}$ sample was then tested to $0.83 \%$ applied strain, which at this ply thickness is very close to AE onset but does not exceed it, before the machining of a thin $(2 \mathrm{~mm})$ slot in the middle of the sample prior to infiltration. This allowed the penetrant solution to enter any potential crack from the center of the specimen as well as from its free edge, revealing any damage originating at the center of the sample. A summary of the selected samples used for interrupted testing can be found in Table 1.

\subsection{Numerical Study}

A FE model was built using a multi-scale "embedded cell" modelling approach in which a finely discretised region corresponding to the $90^{\circ}$ ply was embedded in a larger continuum model of the laminate, where the total model length was at least three times the embedded cell length. To account for the differences that were observed in microscopy, microstructures taken from actual samples were used to build the micromechanical zones of the embedded cell. Either manual fibre identification or an in-house Matlab script working through grey level thresholding, erosion and watershed algorithm were used to reconstruct the fibre centre locations. The fibres' cross sections were then modelled 
as circles of varying diameter, with the goal to be as close as possible to the nominal fibre diameter whilst allowing a fibre separation gap large enough to fit at least one properly conditioned matrix FE element (minimum 5\% of the nominal diameter). This embedded cell approach was shown to work well in the past, as demonstrated in the work of Canal et al. [9]. A transition zone with increasing matrix and interface fracture properties was built-in at the edges of the embedded cell to avoid localization at the interface with the continuum model, and the simulation results were only evaluated outside of these zones. The function used to this purpose is shown on Fig. 2. The embedded cell boundaries are not simple straight edges but rather follow the outer fibres as this is a better way to represent how two adjacent plies actually "interlock" with each other in the observed laminates, where no clear resin rich interply interface could be observed in the samples used.

Three different microstructures, one for each of $\mathrm{t}=30 \mu \mathrm{m}, 68 \mu \mathrm{m}$ and $150 \mu \mathrm{m}$, were embedded in a $[0 / 45 / 90 /-45 / 0]$ stack to replicate the stress state in a quasi-isotropic sample. It was validated that this subjected the embedded cell to the same stress state as an internal $90^{\circ}$ ply would be experiencing in the core of the laminate. The obtained microstructures were used in a 3D model representing a thin slice $(4 \mu \mathrm{m})$ of material, with the embedded cell 10 to 20 times longer than the ply thickness, and the continuum zone length on each side of it at least as long. Because of the inherent numerical instabilities, the problem was solved using a dynamic explicit solver (Abaqus ${ }^{\circledR}$ Explicit) with mass scaling recalculated at each increment to represent the quasi-static response of the material. A study was performed on the variable mass scaling's desired stable time increment to ensure that it was converged at the chosen value of $5 \times 10^{-6}$.

In order to simulate damage events in the bulk of the material, boundary conditions must be enforced to reach a plane-strain state of stress, namely a symmetry on the front side of the model and a planarity constraint on all the nodes of the back face to allow plane displacements due to Poisson effects. These 
boundary conditions are illustrated on Fig. 3 for the $68 \mu \mathrm{m}$ model case.

The free edge behaviour was simulated by a submodelling approach, where the submodel was defined as the micromodelled zone and a part of its homogenised neighbouring plies only, with the same mesh as the bulk model. The displacement field imposed on the boundaries of this submodel, as shown on Fig. 4, was driven by the previously calculated displacement field of a larger continuum model discretised with a coarser and highly biased mesh, subjected to the same boundary conditions as the bulk model but without planarity constraint. This allowed the imposition a realistic 3D displacement boundary condition on the submodel, thus allowing a good representation of the stress-state at the free edge of the samples without having to run a full 3D model of the micromodelled zone. The continuum model used to drive the submodel represents the half width of a physical sample $(12 \mathrm{~mm})$ and a length 10 times longer than the micromodelled zone, which is sufficient to ensure that no undesirable edge effects are imposed upon the submodel.

The mesh uses the C3D8R and C3D6 element formulations offered by Abaqus ${ }^{\circledR}$, with a typical element size of $20 \mu \mathrm{m}$ in the homogenised region and $0.5 \mu \mathrm{m}$ in the embedded cell region. The curvature control parameters used for the meshing algorithm resulted in the definition of about 30 element over the perimeter of the fibres to ensure that the fibre-matrix interface can be discretised finely enough. A single element was used in the depth $(4 \mu \mathrm{m})$ of the model resulting in a mesh varying between $390 \mathrm{k}$ nodes for the $30 \mu \mathrm{m}$ model and 1 Mio nodes for the $150 \mu \mathrm{m}$ model. The mesh of the $150 \mu \mathrm{m}$ model is shown on Fig. 5.

The material properties described below, summarised in Table 2, were partially taken from [1], and amplified by additional experimental tests performed for this work. These properties were kept constant throughout this study to ensure that the effects observed were only caused by the changes of microstructure and ply thickness. The thermal residual stresses were neglected in this analysis due to the low curing temperature of the resin used $\left(80^{\circ} \mathrm{C}\right)$, which only leads to a maximum of 9.3 MPa as calculated by classical laminate theory. Furthermore, as the neat resin was observed to exhibit significant creep under load at room 
temperature, it is expected that the highly stressed zones will experience a significant relaxation during the cooling phase, which further reduces their influence on damage response.

Simulation parameters : Fibres

A transversely isotropic elastic model was used to model the fibres. It relies on the properties published by the fibre manufacturer for the longitudinal direction. The transverse properties were obtained by inverting the Chamis semi-empirical micromechanical model [18] based on the experimental transverse characterization of the material used. The transverse-transverse Poisson ratio, calculated as $\nu_{23}=\frac{E_{2}}{2 G_{23}}-1$, exceeded physically achievable values and was therefore capped at 0.45 . The calculated fibre transverse modulus $E_{2}^{f}$ was within the standard deviation of the values obtained experimentally by nanoindentation on the same kind of fibres by Maurin et al. [19] which in turn were in good agreement with the generally accepted values found in Hughes [20].

Simulation parameters : Matrix

The matrix was modelled using a hyperbolic Drucker-Prager model with regularised damage $([9,21])$ and non-associated flow based on properties measured on bulk matrix specimens. The general exponent formulation of this model offered by Abaqus $\left.{ }^{(}\right)$was used, and its parameters identified by least square fitting of three points, as shown on Fig. 6. The two first ones are the uniaxial tensile $\left(\sigma_{t}^{y}\right)$ and uniaxial compressive $\left(\sigma_{c}^{y}\right)$ yield strength which were measured experimentally following the ISO 527-2/93 [22] standard for the tensile tests and based on the ASTM D695 standard [23] for the compressive test. The last point is the initial hydrostatic tensile strength $p_{t}$ which was defined by the introduction of $\sigma_{t}^{y}$ and $\sigma_{c}^{y}$ values in the yield model proposed by Melro et al. [24] in a triaxial tensile stress-state. The flow-angle $\beta$ can then be retrieved by a tangent calculation of the resulting potential function at high confining pressure.

The tensile hardening as well as critical damage initiation strain (ultimate plastic strain) could not simply be defined as the ones obtained experimentally due 
to the notable size-effects that such tests present, as shown by Fiedler et al. [25] and Hobbiebrunken et al. [26]. Considering that the matrix properties at the micro-level are used in this simulation, an extrapolation using a second order polynomial fit was performed on the averaged experimental tensile stress-strain curve until a perfectly plastic behaviour is reached (horizontal tangent) to extend the ductility of the material. The resulting curve, shown on Fig. 7 is in good agreement with the experimental results obtained on very small samples [25]. The strain at onset of damage in tension $\epsilon_{t}^{c}$ was then defined considering an elastic offloading from the last point in the extended stress-strain curve.

It can be observed that if the extended behaviour is considered, the hydrostatic strength calculated as proposed is in good agreement with both the void initiation failure criterion $\sigma_{H} \geq \sigma_{u t} / 3$ relating the hydrostatic strength $\sigma_{H}$ to the uniaxial strength $\sigma_{u t}$, and previous experimental measurements, both discussed by Gross et al. [27].

Once the critical strain is reached, a linear softening, energy based regularised damage model reduces the stiffness of the matrix elements. The damage variable SDEG is defined as the scalar stiffness degradation variable (Ductile damage model in Abaqus [28]).

Finally, nano-indentation tests were performed on cast matrix specimens and the resulting force-displacement curves used for the inverse-identification of the dilatation angle $\Psi$. A $2 \mathrm{D}$ axisymetric FE model is used to this effect where the indenter tip is modelled with a $70.3^{\circ}$ equivalent half-angle to simulate the Berkovitch tip used experimentally. These simulations were performed using Abaqus Explicit, with mesh and mass-scaling convergence studies performed to ensure that precise results were obtained. The obtained numerical force-displacement curve is in good approximation to the experimental one, as shown on Fig. 8.

A sensitivity analysis using the bulk embedded cell model was performed on the matrix toughness, using values $G_{C}^{m}=64,128$ and $256 \mathrm{~J} / \mathrm{m}^{2}$. It showed an independence of the first crack appearance to this parameter within the 
tested range. This can be explained by considering the weak interface behaviour exhibited here, where debonding and crack coalescence is the preferential energy dissipation mechanism compared to matrix crack propagation. Consequently, $G_{C}^{m}$ was fixed at the lowest tested value of $64 \mathrm{~J} / \mathrm{m}^{2}$.

\section{Simulation parameters : Interface}

The damage process at the fibre-matrix interface was modelled using the linear softening, energy based, cohesive model present in Abaqus ${ }^{\circledR}$, with the damage variable CSDMG representing the loss of stiffness of the interface due to damage. In order to set the interface stiffness, a small RVE of $4 \mu \mathrm{m}$ thickness containing a single fibre embedded in a matrix cube and meshed similarly to the embedded cell of the main model was defined. The goal was to set the stiffness as low as possible to improve computation time whilst ensuring both a converged force-displacement curve and a continuous stress field in the RVE when submitting it to a transverse tensile stress state.

The normal interface strength was shown to be a parameter to which the embedded cell model is only weakly sensitive, as long as it remains weaker than the matrix. Typically, no difference in applied stress required to reach the first transverse crack could be observed between $\tau_{1}^{0}=20 \mathrm{MPa}$ and $\tau_{1}^{0}=40 \mathrm{MPa}$. It was thus set by an inverse identification process [29], by comparing the transverse tensile strength measured experimentally on unidirectional samples of this material to the simulation of a small RVE of similar fibre volume fraction to the experimental samples, containing 180 randomly placed fibres, and using the same material properties as the main model. Both the transverse tensile and embedded cell laminate simulation were insensitive to the interfacial shear strengths when they were set between the normal interfacial strength and twice that value. They were therefore set to 1.5 times the normal value following [30].

The interface toughness was clearly the dominating parameter of the quasiisotropic embedded cell model, and was consequently set such that the first crack predicted by the bulk model for the $150 \mu \mathrm{m}$ thickness model would be in 
good agreement with the experimentally observed onset of damage measured by acoustic emission for this ply thickness. The obtained value of $3 \mathrm{~J} / \mathrm{m}^{2}$, as well as the other interface properties discussed above, are consistent with the values used by Arteiro et al. [10].

\section{Results and Discussion}

\subsection{Experimental Work}

A change in the damage mechanisms with decreasing ply thickness is observed at the free edge of the samples. Samples with the thickest $(t=300 \mu \mathrm{m})$ plies exhibit the first transverse cracks between 0.3 and $0.32 \%$ strain, as shown on Fig. 9a at $0.31 \%$ strain, which in a few instances appear simultaneously to some free edge delamination and delamination along the $90^{\circ}$ plies. The tips of the transverse cracks then trigger a transverse cracking induced delamination process from $0.5 \%$ strain until the failure of the specimens around $0.8 \%$ strain, as shown on Fig. $9 \mathrm{~b}$ at $0.55 \%$ strain. The specimens made with $150 \mu \mathrm{m}$ plies exhibit a higher onset of transverse cracking at the free edge, found between $0.41 \%$ and $0.51 \%$ as shown on Fig. 9 c for $0.5 \%$ strain. Some less extensive matrix cracking induced delamination appears past $0.8 \%$ strain as shown on Fig. $9 \mathrm{~d}$ at $0.85 \%$ strain. The onset of transverse cracking at the free edge is once again delayed in the samples made with $75 \mu \mathrm{m}$ plies, with the first ones observed between $0.52 \%$ and $0.66 \%$, shown for instance at $0.9 \%$ strain on Fig. 9e. This transverse cracking does however not lead to any delamination with this ply thickness. Finally, for the samples manufactured using the thinnest $(30 \mu \mathrm{m})$ plies, no damage can be observed at the free edge before the final failure as shown on Fig. 9f. To ensure that the optical resolution of the equipment used does not preclude the observation of certain damage, the free edge of selected samples was observed in SEM after failure. Whilst transverse cracks did remain clearly visible in thick and intermediate ply thicknesses, no sign of transverse 
cracking could be found for the thinnest plies as shown on Fig. 10.

The stress at which the first damage was observed at the free edge, as well as the onset of damage defined by acoustic emission and the ultimate strength of the different ply thicknesses tested are shown on Fig. 11. As no free edge damage could be observed for the samples made with $30 \mu \mathrm{m}$ plies, the UTS value is reported there instead of the free edge crack onset for this ply thickness.

One striking feature of the comparison between the free edge observations and the acoustic emission measurements, as shown on Fig. 11, is the drastically different scaling that can be observed between the free edge crack onset and the onset of damage obtained by acoustic emission. The observations performed at the free edge are in good agreement with a $1 / \sqrt{t}$ scaling, as shown in green in Fig. 11. To the contrary, the onset of damage determined by acoustic emission increases much more linearly with decreasing ply thickness, as shown in red in the same figure. Such a discrepancy between these two indicators can only be explained by the fact that their respective underlying mechanisms are different.

These two different mechanisms can be observed in the partially loaded and cut samples. Indeed, for the one manufactured with $150 \mu \mathrm{m}$ plies and loaded until $0.64 \%$ strain, no damage could be observed in the bulk of the sample, whereas the free edge showed obvious signs of transverse cracking, as shown on Fig. 12b. For the similar sample loaded until $0.89 \%$ strain, the free edge reveals much more free edge damage as can be seen on Fig. 12 a, with delamination growing from the transverse cracks and secondary damage propagating into the $\pm 45^{\circ}$ layers or growing within the $90^{\circ}$ plies. At this applied strain, transverse cracks could be observed in the middle of the samples. Finally, the sample manufactured with $75 \mu \mathrm{m}$ plies and loaded until $0.89 \%$ strain, shown on Fig. 12c, reveals a reduced free edge damage compared to the sample manufactured with $150 \mathrm{\mu m}$ plies that was tested up to the same applied strain. Transverse cracking is the only observed damage mechanism, which is consistent with the observa- 
tions made during the in-situ tests. Furthermore, no damage can be observed in the middle of this $75 \mu \mathrm{m}$ sample. It can thus be established that the presence of transverse cracking in the bulk of the samples is linked to the crossing of the acoustic emission threshold as defined in this work (section 2.1).

Further evidence that transverse cracks originate from the free edge of the samples and then propagate into the bulk at the onset of damage defined by acoustic emission is brought by the tomographic observation discussed in section 2.1. Fig. 13 represents a maximum intensity projection performed with Fiji [31] of all the slices laying in a typical $90^{\circ}$ ply, and clearly shows that in both the $\mathrm{t}=150 \mu \mathrm{m}$ and $\mathrm{t}=100 \mu \mathrm{m}$ samples loaded to a stress inferior but close to the acoustic emission onset, no free edge crack propagates markedly into the bulk of the sample (Fig. 13 a,b). To the contrary, in the samples of both $100 \mu \mathrm{m}$ and $150 \mu \mathrm{m}$ ply thicknesses loaded to a stress level superior to the acoustic emission threshold, transverse cracks clearly propagate in the bulk of the $90^{\circ}$ ply (Fig. 13 c,d). The presence of delamination is evident for the $150 \mu \mathrm{m}$ laminate loaded until $0.89 \%$ strain, but it is interesting to note that it does not extend far into the width of the sample despite a stress level very close to failure. Owing to the observation of the failure mode of these samples, it is most likely that the propagation of this delamination throughout the width of the sample is the last damage occurring and immediately leads to the failure of the specimens. No such delamination can be seen in the $100 \mu \mathrm{m}$ laminate despite having been subjected to the same applied strain of $0.89 \%$. Furthermore, the developed crack density at a given load is clearly smaller in the samples made of thinner plies (Fig. $13 \mathrm{c}, \mathrm{d}$ ) which is consistent with [7] but opposite to the trend generally seen at the free edge as for instance in [6].

The $\mathrm{t}=100 \mu \mathrm{m}$ sample used to assess the absence of damage originating from the bulk is shown on Fig. 14. If the machined cut is clearly visible, no transverse cracks are revealed in the bulk, proving that this kind of damage always propagates from the free edges in such samples. 
The angle exhibited by the transverse cracks at the free edge, close to $45^{\circ}$, are due to a large in plane shear stress component induced by the quasi-isotropic laminate chosen, as shown in the stress analysis of section 3.2. This leads to a principal stress at the free edge of the samples which is normal to the observed cracks. This also explains the observed symmetry in crack angle around the specimens' mid-plane due to the symmetry plane of the chosen stacking sequence. Using the tomographic observations, it is possible to assess that this angle steadily decreases until transverse cracks perpendicular to the ply are observed, around $2 \mathrm{~mm}$ into the width of the samples.

In summary, considering the demonstrated different underlying mechanisms between free-edge and bulk behaviour, the increasing strength with decreasing ply thickness observed can be explained by the fact that the behaviour of the samples manufactured using the thickest $(300 \mu \mathrm{m})$ plies is dominated by damage at their free edges. Any damage appearing there immediately propagates into the bulk of the sample. With decreasing ply thickness, the onset of free edge damage is not only delayed, but the ease with which it can propagate towards the center of the sample is also reduced. The onset of damage as recorded by acoustic emission therefore diverges from what is observed at the free edge, until a different failure mechanism such as the translaminar fracture of the $0^{\circ}$ plies becomes predominant, as is the case in the sample manufactured with the thinnest plies $(\mathrm{t}=30 \mu \mathrm{m})$ where the acoustic emission threshold is reached before free edge damage can be observed.

Finally, a comparison can be made between the acoustic emission measurements reported in [1] and the ones performed at a much reduced loading speed during this experimental study, both shown on Fig. 11. For the two largest ply thicknesses, the onset of damage is delayed at the lower loading speed, as the highly loaded free edge region of the $90^{\circ}$ ply region benefits from stress relaxation due to viscoplastic flow. To the contrary, the two smallest ply thicknesses 
show little dependency on the loading rate, which is further proof that thin-ply composites are less sensitive to damage initiation at the free edge.

\subsection{Numerical Work}

The sequence of damage events in the bulk model is remarkably similar for all three simulation. The first damage to appear is fibre-matrix debonding, which initiates for all ply thicknesses around $0.23 \%$ strain. This then leads to local stress concentrators in the matrix, plastic damage accumulation and eventually transverse matrix cracking through coalescence of micro-damage. It is interesting to note that this coalescence always takes place in regions where the fibres are closely packed due to increased stress triaxiality in those regions. The main difference noted in the sequence of events between the three simulations is an increased capability to accumulate distributed damage before localisation with decreasing ply thickness. This is illustrated in Fig. 15 where the average cohesive damage indicator (CSDMG) show a very similar onset and increase for all three ply thicknesses modelled. It is only once coalescence happens and thus damage localises that the remaining matrix ligaments experience an increase of plasticity (PEEQ). Typical damage development is represented in Fig. 16. Another point that was noticed during the model development is the much higher sensitivity of the larger ply thickness models to variations in their microstructures compared to thinner plies, where early localisation could very easily be triggered in highly packed region. This was not observed for thinner plies, and reinforces the importance to use realistic microstructures in the numerical models. The larger microstructure heterogeneity found in thicker plies is believed to be the cause of this phenomenon [32].

The onset of transverse cracking in the numerical models is defined as a local unloading (drop in $\sigma_{x x}$ ) over a zone spanning at least a quarter of the ply thickness in the micro-modelled region, as shown on Fig. 17. This also corresponds to the first drop in averaged stress in the micro-modelled zone due to 
the local stress relaxation induced by the crack-opening. It is interesting to note the typical slanted free edge cracks present in the free edge model compared to the purely transverse cracks of the bulk model, which is in agreement with the experimental observations. The macroscopic stress at which this first crack is detected in the bulk FE simulations is then compared to the one at which the acoustic emission threshold is reached at high loading rate, considering that no viscous model is implemented in the simulations. Similarly, the stress at which cracks are detected in the free edge model are related to the onset of free edge cracking. The results reported on Fig. 11 show both a very good agreement between the bulk model values and the experimental onset of damage defined by acoustic emission, as well as a clear difference in behaviour between the bulk and the free-edge models, with the latter tending towards what is observed experimentally at the free edge.

Regarding the stress-state at the free edge, an analysis of the linear elastic homogenised 3D model used to drive the submodel is performed in order to understand the reason for the angled transverse cracks observed at the free edges. No significant differences are noticed between the different ply thicknesses when computing the mean stress components in the zone corresponding to the embedded cell.

For the $\mathrm{t}=68 \mathrm{\mu m}$ model, at an applied strain of $0.95 \%$, the mean transverse tensile stress $\bar{\sigma}_{22}$ in the $90^{\circ}$ layer at the free edge is nearly doubled compared to the mean stress obtained from CLT prediction, with a mean value of $115 \mathrm{MPa}$. Simultaneously, the $90^{\circ}$ ply at the free edge is under a tensile out of plane stress $\bar{\sigma}_{33}$ close to the same mean value. This "through the thickness" stress tends to split the $\pm 45^{\circ}$ layers away from the $90^{\circ}$ one and thus promotes delamination. Furthermore, the mean shear stresses $\bar{\tau}_{12}$ and $\bar{\tau}_{13}$ are negligible within the $90^{\circ}$ ply, increasing only very close to the ply boundaries. However, the component $\bar{\tau}_{23}$ cannot be neglected, as it reaches a mean value of $75 \mathrm{MPa}$, as shown on Fig. 18. At the free edges, the $90^{\circ}$ ply within the selected quasi-isotropic laminates is thus under combined bi-axial tension and transverse shear. It is this 
combined stress-state that is responsible for the angle of the transverse cracks observed at the free edge. With a principal stress analysis, the angle of the crack can be easily deduced, assuming that the crack is normal to the principal stress direction. With the above mentioned values, it is possible to obtain the crack angle $\phi=1 / 2 \arctan \left[\bar{\tau}_{23} /\left(\bar{\sigma}_{22}-\bar{\sigma}_{33} / 2\right)\right]=42.5^{\circ}$ which is very close to what is observed experimentally.

Regarding the onset of damage scaling with respect to ply thickness, the finite size of the process zone observed during crack development, as shown by the unbroken matrix ligaments on Fig. 16 (damage evolution in $68 \mu \mathrm{m}$ ply) is of utmost importance. In such a case, the underlying assumptions of LEFM of a fully developed process zone of negligible size is not satisfied. Due to the strong confinement exerted by the neighbouring plies, the crack opening displacement remains very limited in thin plies, which prevents a complete degradation of the ductile matrix ligaments. Thus, only a fraction of the total fracture energy can effectively be dissipated in thin plies. An R-curve effect of the critical ERR associated to transverse cracking is therefore to be expected, as postulated in [15]. To evaluate this hypothesis, the energy dissipation increment during crack nucleation was computed from the embedded cell simulation and an effective critical ERR was computed as the energy dissipated during crack growth divided by the crack area. As shown in Fig 19, the simulation results show a clear reduction of the critical ERR with decreasing ply thickness. The linear scaling in onset of damage is thus attributed to a combination of this reduction of apparent toughness due to an incomplete fracture process zone with the well known ply confinement effect described in the in-situ strength model proposed by Camanho et al. [12]. A modification of this latter model to include the discussed reduction of ERR with decreasing ply thickness was recently proposed by Catalanotti [33]. 


\section{Summary and Conclusion}

The appearance of damage in tensile CFRP specimens was monitored in-situ simultaneously at the free edge using a video microscope and in the bulk using acoustic emission. It was shown that their respective onset of damage scalings in terms of the ply thickness differed strongly, indicating two different events. A good correlation between the acoustic onset of damage criterion and the actual observable propagation of transverse cracks into the bulk of the samples was demonstrated by ex-situ micrographies of cut samples and tomographic observations. Furthermore, it was shown that transverse cracks do not originate from the center of the specimens but instead propagate from the free edge into the bulk. Free edge cracking and bulk transverse cracking are thus two different mechanisms with different stress onsets. This propagation of transverse cracks from the free edge into the bulk was shown to be specific to intermediate ply thicknesses, typically in the $50 \mu \mathrm{m}$ to $200 \mu \mathrm{m}$ range, as delamination dominates the damage behaviour of the samples when larger plies are used, whereas the translaminar fracture strength of the $0^{\circ}$ plies becomes dominant with thinner ones.

The onset of damage predicted by the embedded cell FE model in the bulk of the material showed a very good agreement with the values obtained experimentally using acoustic emission. When the free-edge behaviour was simulated, using what is essentially the same model using different boundary conditions, results in good agreement with the experimentally observed transverse cracking onset at the free edge were obtained. Attention should therefore be paid in the future to not compare plane-strain models of transverse cracking to experimental free edge observations without first ensuring that these observations are representative of the damage in the bulk of the material. The finite size of the fracture process zone could also be observed in the FE models, which leads to a decrease of apparent toughness for thinner plies. The discrepancy between the experimental onset of damage measured by acoustic emission and LEFM-based 
analytical models can thus be explained by the incomplete development of the fracture process zone in confined thin plies which limits the ERR and therefore leads to a deviation from the $1 / \sqrt{t}$ scaling derived from LEFM under the assumption of constant ERR.

Further experimental characterization of the crack propagation into the bulk of the samples as well as an extension of this work to other materials should help gain an insight into the generic mechanisms at play, paving the way to modelling of the in-situ strength mechanism for very low ply thicknesses at the meso- and macro-scale.

\section{Acknowledgements}

This research was funded by the Swiss National Science Foundation, project 200021_156207. The authors wish to thank North Thin Ply Technology for the material supply and Gary Perrenoud from PIXE/EPFL for the X-Ray scans.

\section{References}

[1] R. Amacher, J. Cugnoni, J. Botsis, L. Sorensen, W. Smith, and C. Dransfeld. Thin ply composites : Experimental characterization and modeling of size-effects. Composites Science and Technology, 101 :121-132, 2014.

[2] A. Parvizi, K. W. Garrett, and J. E. Bailey. Constrained cracking in glass fibre-reinforced epoxy cross-ply laminates. Journal of Materials Science, 13(1) :195-201, 1978.

[3] S. Sihn, R. Y. Kim, K. Kawabe, and S. W. Tsai. Experimental studies of thin-ply laminated composites. Composites Science and Technology, 67(6) :996-1008, 2007.

[4] M. R. Wisnom, B. Khan, and S. R. Hallett. Size effects in unnotched tensile strength of unidirectional and quasi-isotropic carbon/epoxy composites. Composite Structures, 84(1) :21-28, 2008. 
[5] H. Saito, H. Takeuchi, and I. Kimpara. Experimental evaluation of the damage growth restraining in $90^{\circ}$ layer of thin-ply cfrp cross-ply laminates. Advanced Composite Materials, 21(1) :57-66, 2012.

[6] T. A. Sebaey, J. Costa, P. Maimí, Y. Batista, N. Blanco, and J. A. Mayugo. Measurement of the in situ transverse tensile strength of composite plies by means of the real time monitoring of microcracking. Composites Part B : Engineering, 65 :40-46, 2014.

[7] T. Yokozeki, Y. Aoki, and T. Ogasawara. Experimental characterization of strength and damage resistance properties of thin-ply carbon fiber/toughened epoxy laminates. Composite Structures, 82(3) :382-389, February 2008 .

[8] L. P. Canal, J. Segurado, and J. LLorca. Failure surface of epoxy-modified fiber-reinforced composites under transverse tension and out-of-plane shear. International Journal of Solids and Structures, 46(11-12) :2265-2274, 2009.

[9] L. P. Canal, C. González, J. Segurado, and J. LLorca. Intraply fracture of fiber-reinforced composites : Microscopic mechanisms and modeling. Composites Science and Technology, 72(11) :1223-1232, 2012.

[10] A. Arteiro, G. Catalanotti, A. R. Melro, P. Linde, and P. P. Camanho. Micro-mechanical analysis of the in situ effect in polymer composite laminates. Composite Structures, 116(1) :827-840, 2014.

[11] A. Arteiro, G. Catalanotti, J. Reinoso, P. Linde, and P. P. Camanho. Simulation of the mechanical response of thin-ply composites : From computational micro-mechanics to structural analysis. Archives of Computational Methods in Engineering, pages -, 2018.

[12] P. P. Camanho, C. G. Dávila, S. T. Pinho, L. Iannucci, and P. Robinson. Prediction of in situ strengths and matrix cracking in composites under transverse tension and in-plane shear. Composites Part A : Applied Science and Manufacturing, 37(2) :165-176, 2006. 
[13] G. J. Dvorak and N. Laws. Analysis of progressive matrix cracking in composite laminates ii. first ply failure. Journal of Composite Materials, 21(4):309-329, April 1987.

[14] Test method for tensile properties of polymer matrix composite materials, 2008.

[15] J. Cugnoni, R. Amacher, S. Kohler, J. Brunner, E. Kramer, C. Dransfeld, W. Smith, K. Scobbie, L. Sorensen, and J. Botsis. Towards aerospace grade thin-ply composites : Effect of ply thickness, fibre, matrix and interlayer toughening on strength and damage tolerance. Composites Science and Technology, pages -, 2018.

[16] R. Amacher, W. Smith, C. Dransfeld, J. Botsis, and J. Cugnoni. Thin ply : From size-effect characterization to real life design. In CAMX 2014 - Composites and Advanced Materials Expo : Combined Strength. Unsurpassed Innovation., pages -, 2014.

[17] F. Sket, A. Enfedaque, C. Alton, C. González, J. M. Molina-Aldareguia, and J. Llorca. Automatic quantification of matrix cracking and fiber rotation by x-ray computed tomography in shear-deformed carbon fiber-reinforced laminates. Composites Science and Technology, 90 :129-138, 2014.

[18] R. Younes, A. Hallal, F. Fardoun, and F. H. Chehade. Composites and Their Properties, chapter Comparative Review Study on Elastic Properties Modeling for Unidirectional Composite Materials,. 2012.

[19] R. Maurin, P. Davies, N. Baral, and C. Baley. Transverse properties of carbon fibres by nano-indentation and micro-mechanics. Applied Composite Materials, 15(2) :61-, 2008.

[20] J. D. H. Hughes. The carbon fibre/epoxy interface - a review. Composites Science and Technology, 41(1) :13-45, 1991. 
[21] T. J. Vaughan and C. T. McCarthy. Micromechanical modelling of the transverse damage behaviour in fibre reinforced composites. Composites Science and Technology, 71(3):388-396, 2011.

[22] Iso 527-2 :1993 : Plastics - determination of tensile properties - part 2 : Test conditions for moulding and extrusion plastics.

[23] Standard test method for compressive properties of rigid plastics, 2015.

[24] A. R. Melro, P. P. Camanho, F. M. Andrade Pires, and S. T. Pinho. Micromechanical analysis of polymer composites reinforced by unidirectional fibres : Part i-constitutive modelling. International Journal of Solids and Structures, 50(11-12) :1897-1905, 2013.

[25] B. Fiedler, M. Hojo, S. Ochiai, K. Schulte, and M. Ando. Failure behavior of an epoxy matrix under different kinds of static loading. Composites Science and Technology, 61(11) :1615-1624, 2001.

[26] T. Hobbiebrunken, B. Fiedler, M. Hojo, and M. Tanaka. Experimental determination of the true epoxy resin strength using micro-scaled specimens. Composites Part A : Applied Science and Manufacturing, 38(3) :814-818, 2007.

[27] T. S. Gross, H. Jafari, J. Kusch, I. Tsukrov, B. Drach, H. Bayraktar, and J. Goering. Measuring failure stress of rtm6 epoxy resin under purely hydrostatic tensile stress using constrained tube method. Experimental Techniques, 41(1) :45-50, 2017.

[28] Dassault Systemes. Abaqus 6.12 Online Documentation. 2012.

[29] S. Kohler. Multiscale experimental characterisation and modelling of transverse cracking in thin-ply composites. 2019.

[30] S. Ogihara and J. Koyanagi. Investigation of combined stress state failure criterion for glass fiber/epoxy interface by the cruciform specimen method. Composites Science and Technology, 70(1) :143-150, 2010. 
[31] J. Schindelin, I. Arganda-Carreras, E. Frise, V. Kaynig, M. Longair, T. Pietzsch, S. Preibisch, C. Rueden, S. Saalfeld, B. Schmid, J.-Y. Tinevez, D. J. White, V. Hartenstein, K. Eliceiri, P. Tomancak, and A. Cardona. Fiji : an open-source platform for biological-image analysis. Nature Methods, 9 :676-, June 2012.

[32] F. Naya, G. Pappas, and J. Botsis. Micromechanical study on the origin of fiber bridging under interlaminar and intralaminar mode i failure. Composite Structures, $210: 877$ - 891, 2019.

[33] G. Catalanotti. Prediction of in situ strengths in composites : Some considerations. Composite Structures, 207 :889-893, 2019. 
TABLE 1: Summary of the selected samples used for the interrupted tests

\begin{tabular}{|c|c|c|}
\hline \multirow{3}{*}{ ply thickness ( $\mu \mathrm{m})$} & applied strain (\%) & applied strain (\%) \\
\hline & (observation technique used) & (observation technique used) \\
\hline & before $A E$ onset & past $A E$ onset \\
\hline 75 & 0.89 (sample sectioning) & - \\
\hline \multirow{3}{*}{100} & 0.64 (tomography) & \\
\hline & 0.83 (tomography) & 0.89 (tomography) \\
\hline & 0.83 (tomography with slit) & \\
\hline \multirow{2}{*}{150} & 0.64 (sample sectioning) & 0.89 (sample sectioning) \\
\hline & 0.64 (tomography) & 0.89 (tomography) \\
\hline
\end{tabular}


TABLE 2: Material properties used in the FE model, taken from [1] and manufacturer's specifications. Newly obtained or assumed data as discussed in this work is denoted by a (*)

\begin{tabular}{|c|c|}
\hline \multicolumn{2}{|l|}{ Fibre Properties } \\
\hline Density $\left(\left(\mathrm{kg} \mathrm{m}^{-3}\right)\right)$ & 1750 \\
\hline Young's modulus $\mathrm{E}_{11}^{f}(\mathrm{GPa})$ & 377 \\
\hline * Young's modulus $\mathrm{E}_{22}^{f}(\mathrm{GPa})$ & 11 \\
\hline$*$ Poisson ratio $\nu_{12}^{f}(-)$ & 0.29 \\
\hline$*$ Poisson ratio $\nu_{23}^{f}(-)$ & 0.45 \\
\hline * Shear Modulus G $\mathrm{f}_{12}^{f}(\mathrm{GPa})$ & 44 \\
\hline * Shear Modulus $\mathrm{G}_{23}^{f}(\mathrm{GPa})$ & 3.5 \\
\hline \multicolumn{2}{|l|}{ UD lamina Properties } \\
\hline Density $\left(\mathrm{kg} \mathrm{m}^{-3}\right)$ & 1500 \\
\hline Young's modulus $\mathrm{E}_{11}(\mathrm{GPa})$ & 220 \\
\hline Young's modulus $\mathrm{E}_{22}(\mathrm{GPa})$ & 7.01 \\
\hline Poisson ratio $\nu_{12}(-)$ & 0.314 \\
\hline Shear Modulus $\mathrm{G}_{12}(\mathrm{MPa})$ & 4661 \\
\hline Shear Modulus $\mathrm{G}_{23}(\mathrm{MPa})$ & 2417 \\
\hline \multicolumn{2}{|l|}{ Matrix Properties } \\
\hline Density $\left(\mathrm{kg} \mathrm{m}^{-3}\right)$ & 1200 \\
\hline Young's modulus $E_{m}(\mathrm{MPa})$ & 3261 \\
\hline Poisson ratio $\nu_{m}(-)$ & 0.35 \\
\hline * Drucker-Prager friction angle $\beta\left(^{\circ}\right)$ & 24 \\
\hline * Drucker-Prager dilatation angle $\Psi\left(^{\circ}\right)$ & 35 \\
\hline * Init. hydrostat. tensile strength $p_{t}(\mathrm{MPa})$ & 35 \\
\hline * Onset of damage compressive strain $\epsilon_{c}^{c}(\%)$ & 25 \\
\hline * Onset of damage shear strain $\epsilon_{s}^{c}(\%)$ & 1.75 \\
\hline * Onset of damage tensile strain $\epsilon_{t}^{c}(\%)$ & 1.75 \\
\hline * Critical Energy Release Rate $G_{m}\left(\mathrm{~J} / \mathrm{m}^{2}\right)$ & 64 \\
\hline \multicolumn{2}{|l|}{ Interface properties } \\
\hline * Interface normal stiffness $\mathrm{K}_{n n}\left(\mathrm{~N} / \mathrm{mm}^{3}\right)$ & $2 \mathrm{E} 7$ \\
\hline * Interface shear stiffness $\mathrm{K}_{s s} \& \mathrm{~K}_{t t}\left(\mathrm{~N} / \mathrm{mm}^{3}\right)$ & $4 \mathrm{E} 7$ \\
\hline * Interface normal strength $\tau_{1}^{0}(\mathrm{MPa})$ & 20 \\
\hline${ }^{*}$ Interface shear strength $\tau_{2}^{0} \& \tau_{3}^{0}(\mathrm{MPa})$ & 30 \\
\hline * Interface critical Energy Release Rate $G_{i}\left(\mathrm{~J} / \mathrm{m}^{2}\right)$ & 3 \\
\hline
\end{tabular}




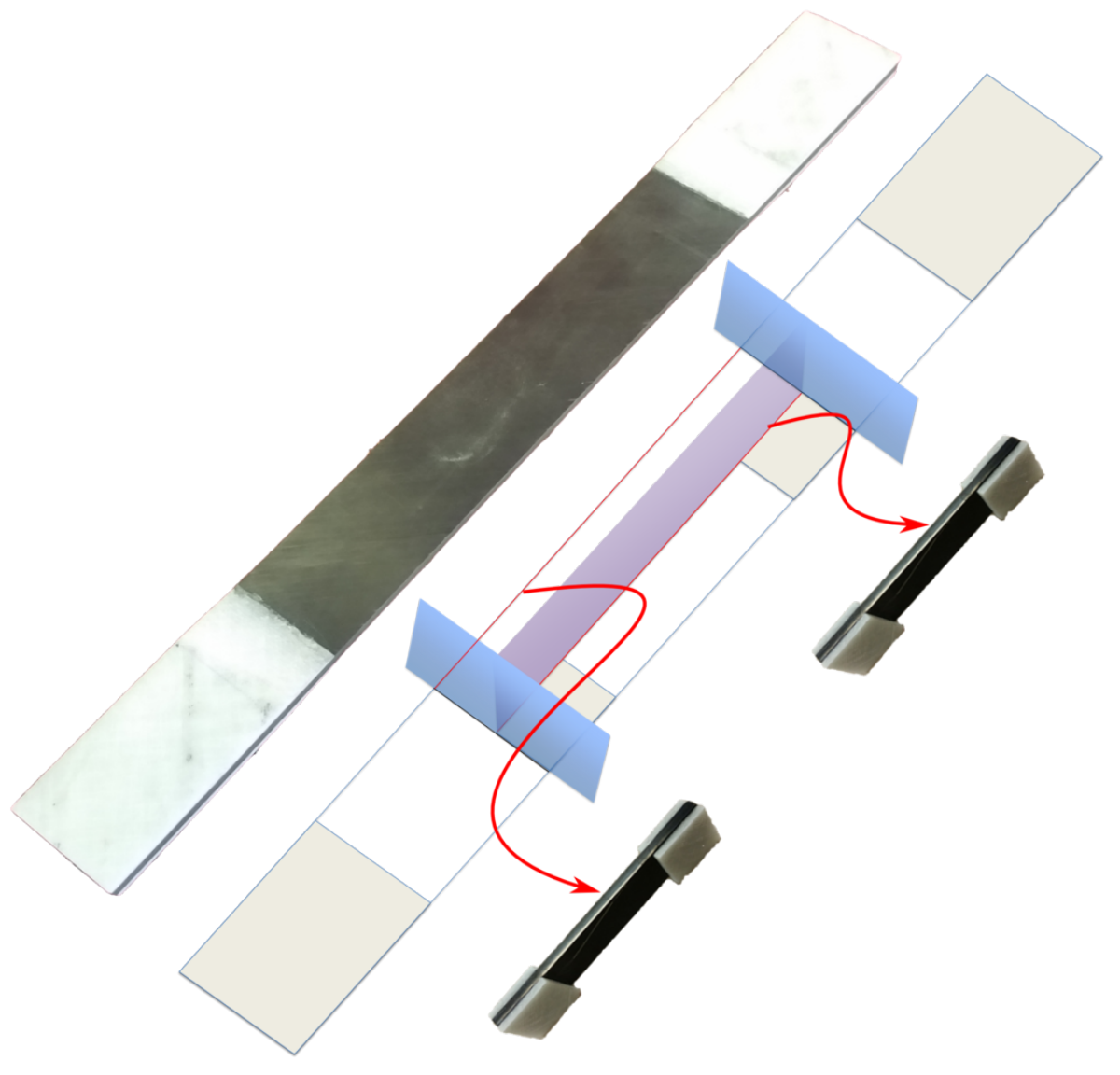

Figure 1: Schematic of the cut done to the samples to reveal the center of the specimens 


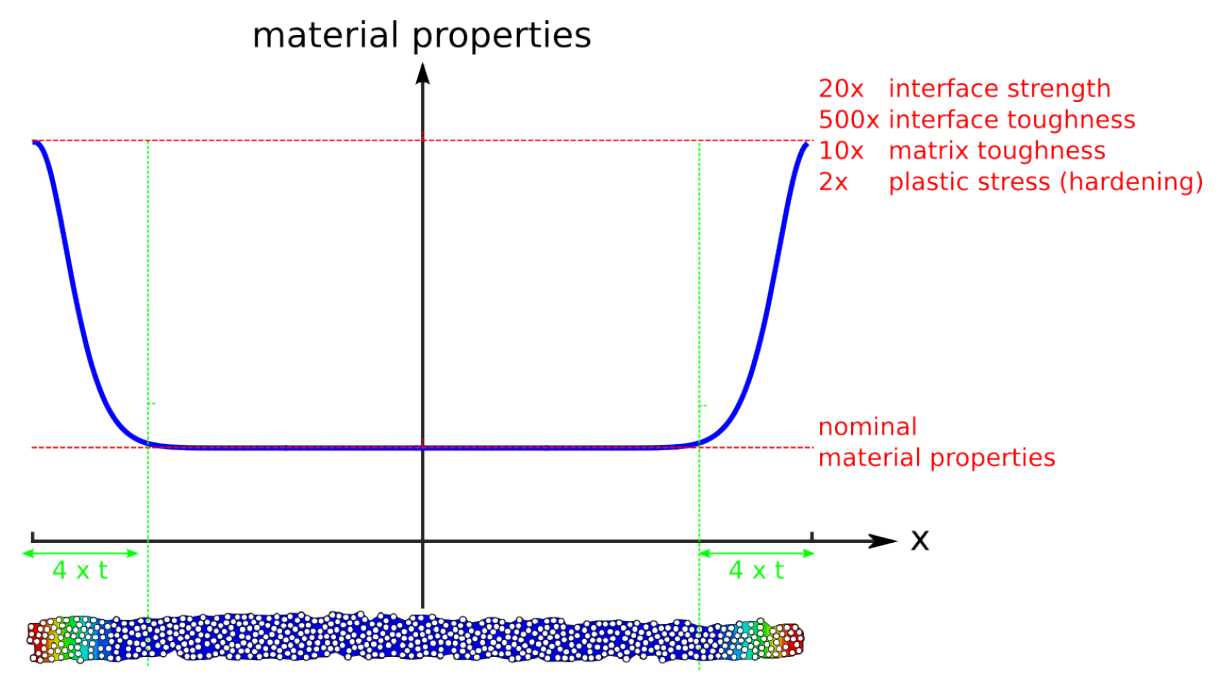

Figure 2: Transition zone used at the edge of the embedded cells, showing the function used to increase the fracture properties as a function of the $\mathrm{x}$ position. The overlaid embedded cell at the bottom with contour plots varying from the nominal properties to the maximal ones shows an example of its application 

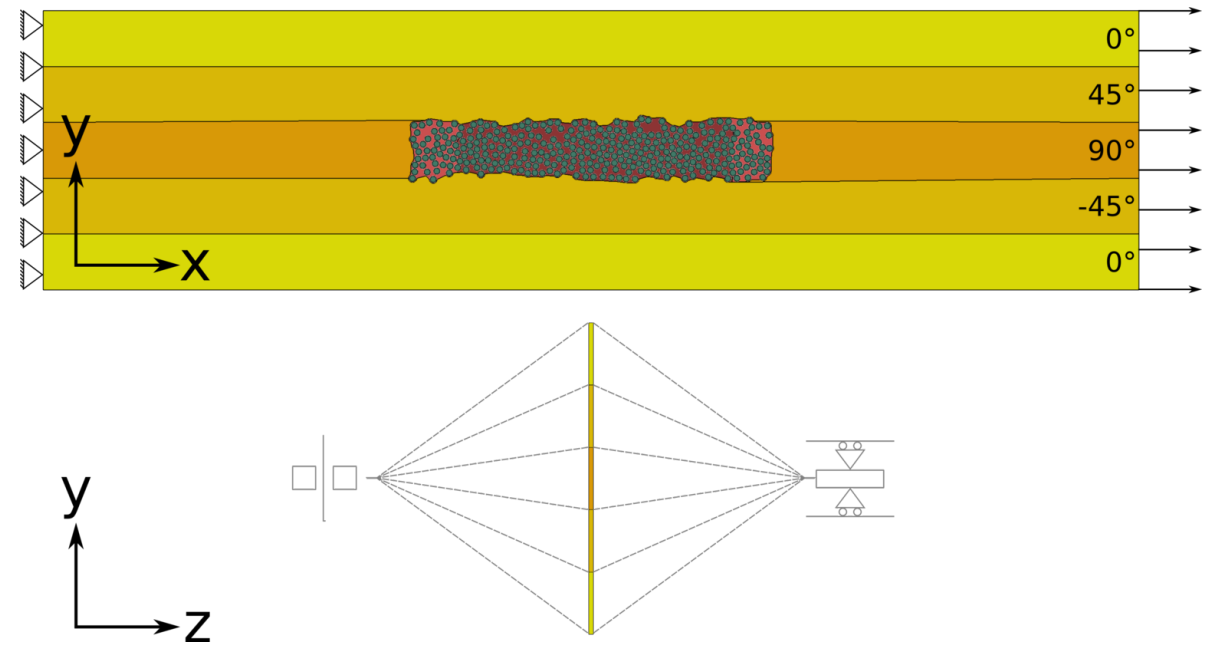

Figure 3: Bulk numerical model description. The applied boundary condition impose a planestrain state of stress. The transition zone is highlighted by a lighter red than the rest of the matrix, with all fibres coloured green. 

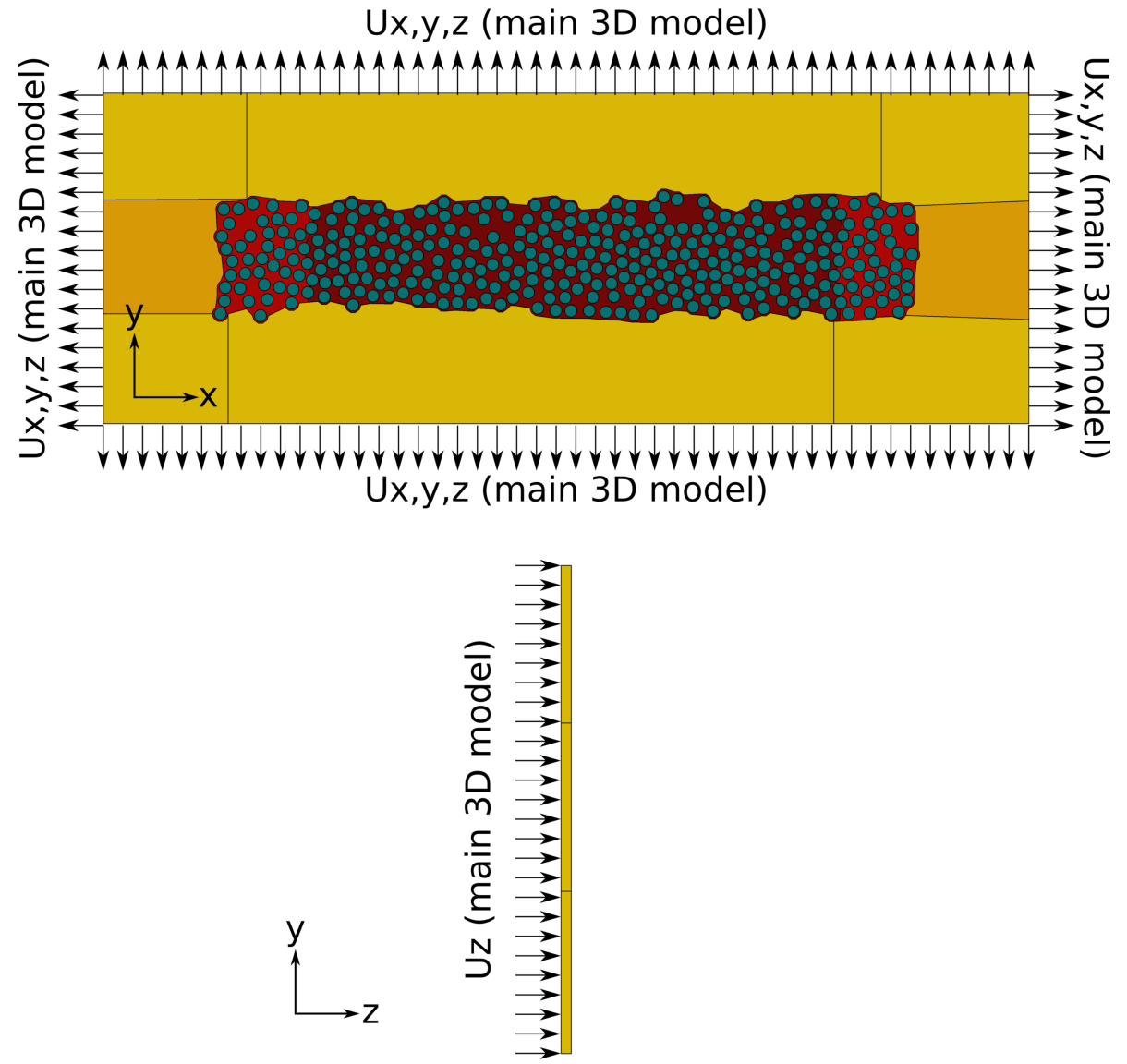

Figure 4: Submodel numerical model description, used to represent the free edge behaviour. It is driven by the displacements fields obtained from a linear elastic, ply-level homogenised model in the $\mathrm{x}$ and $\mathrm{y}$ directions in the microstructure's plane, and in the $\mathrm{z}$ direction on its back face. 


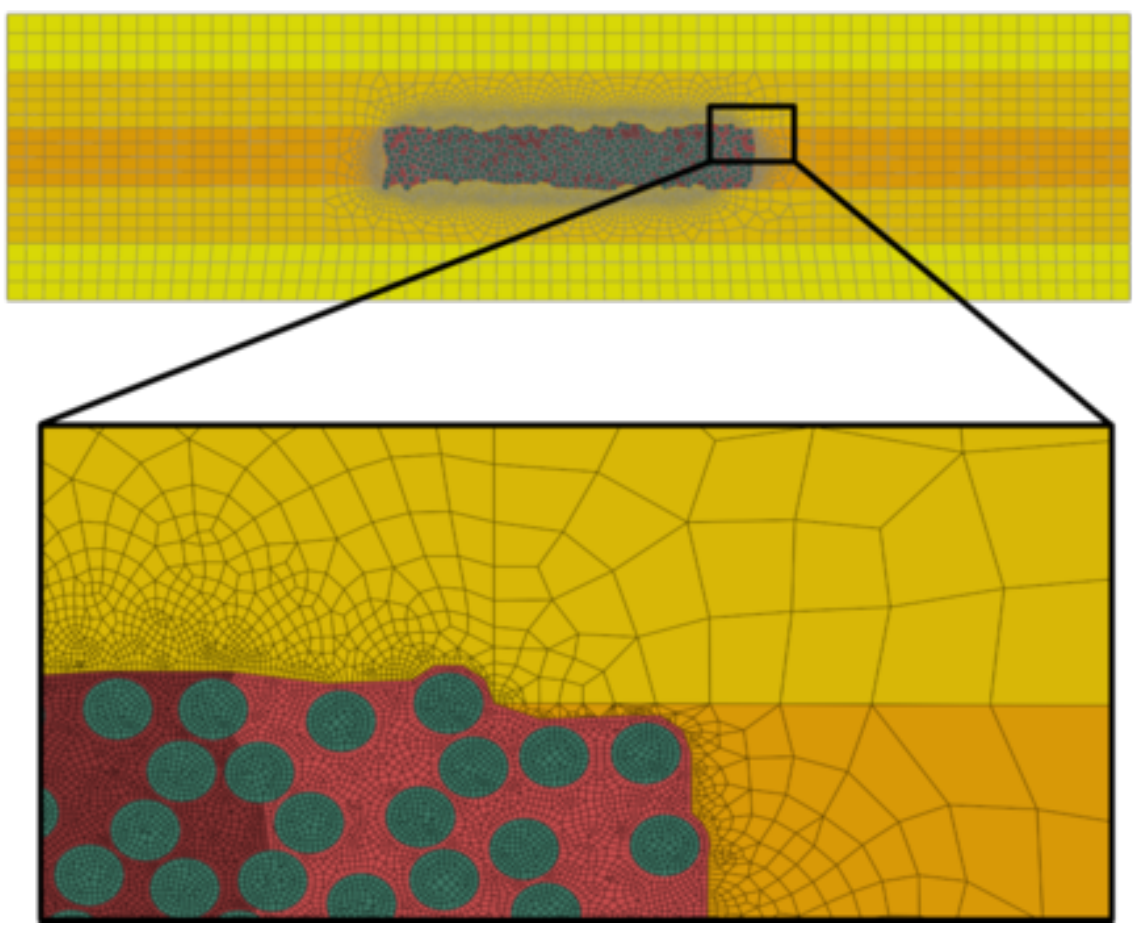

FIGURE 5: illustration of the mesh on the $t=150 \mu \mathrm{m}$ model 


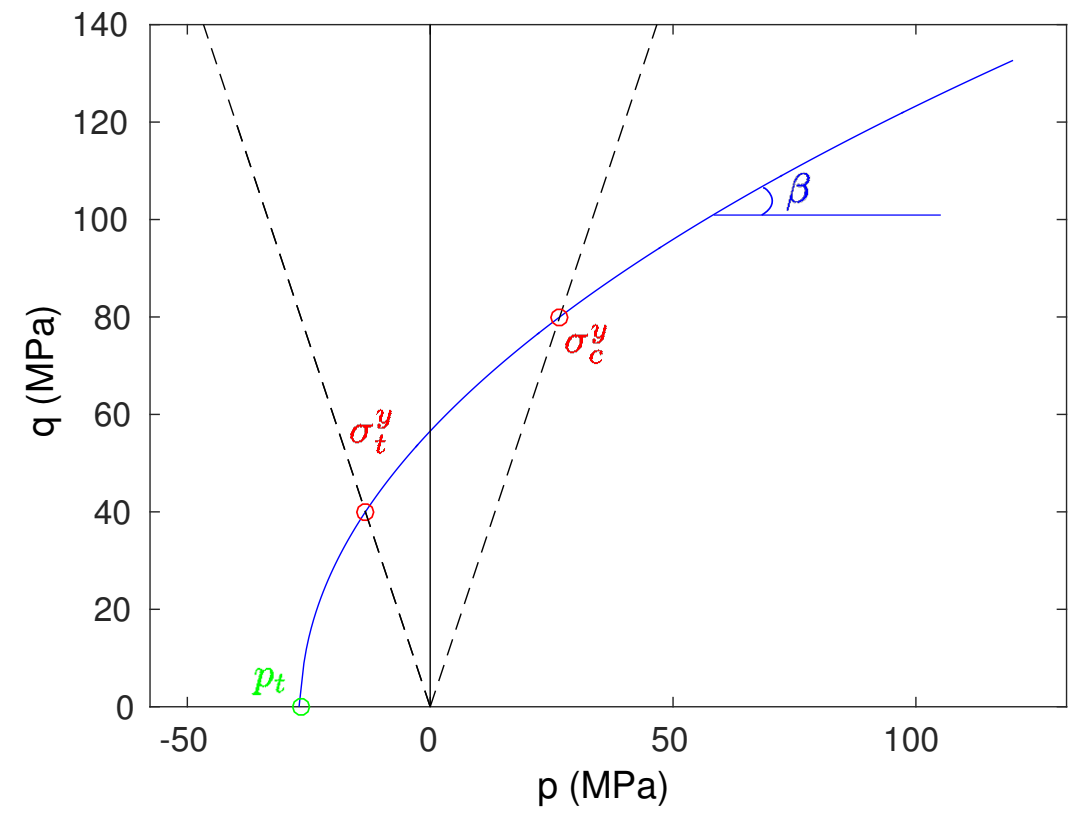

Figure 6: Identified Drucker-Prager model, with the experimentally measured uniaxial results shown in red and the deduced hydrostatic strength shown in green. $\mathrm{p}$ is the hydrostatic pressure and q the equivalent von Mises stress 


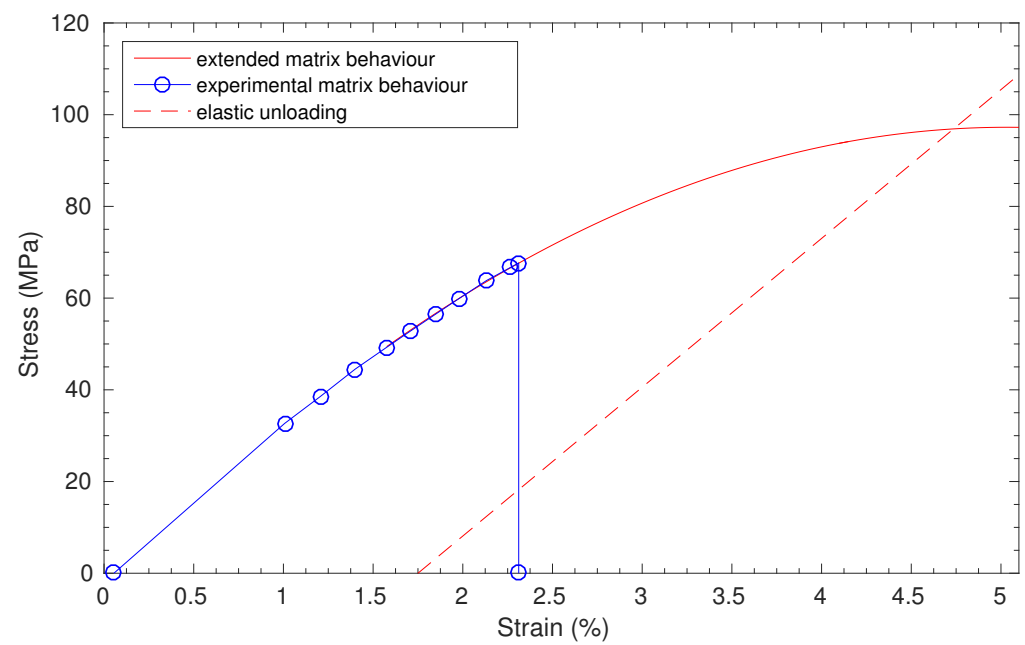

FIGURE 7: TP80 elasto-plastic model, with the experimental values in blue and extended curve in red. The dashed line is the elastic unloading, used to predict the maximal plastic strain 


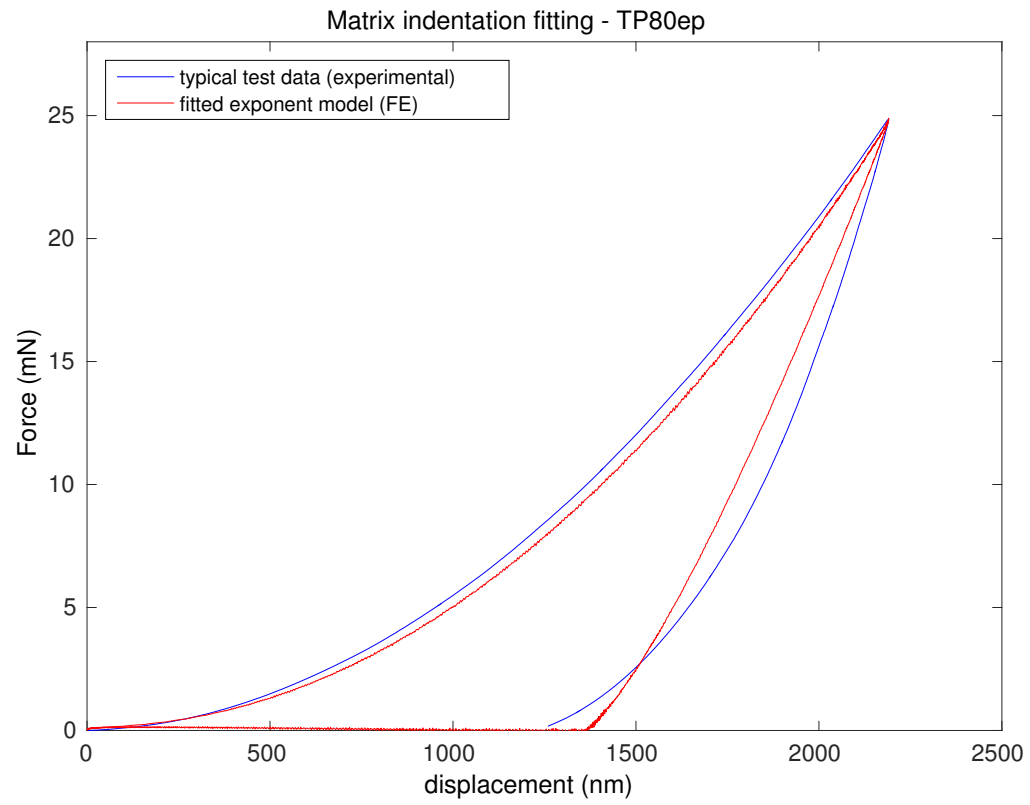

Figure 8: Nano-indentation Force-Displacement comparison between experimental and numerical identified model 


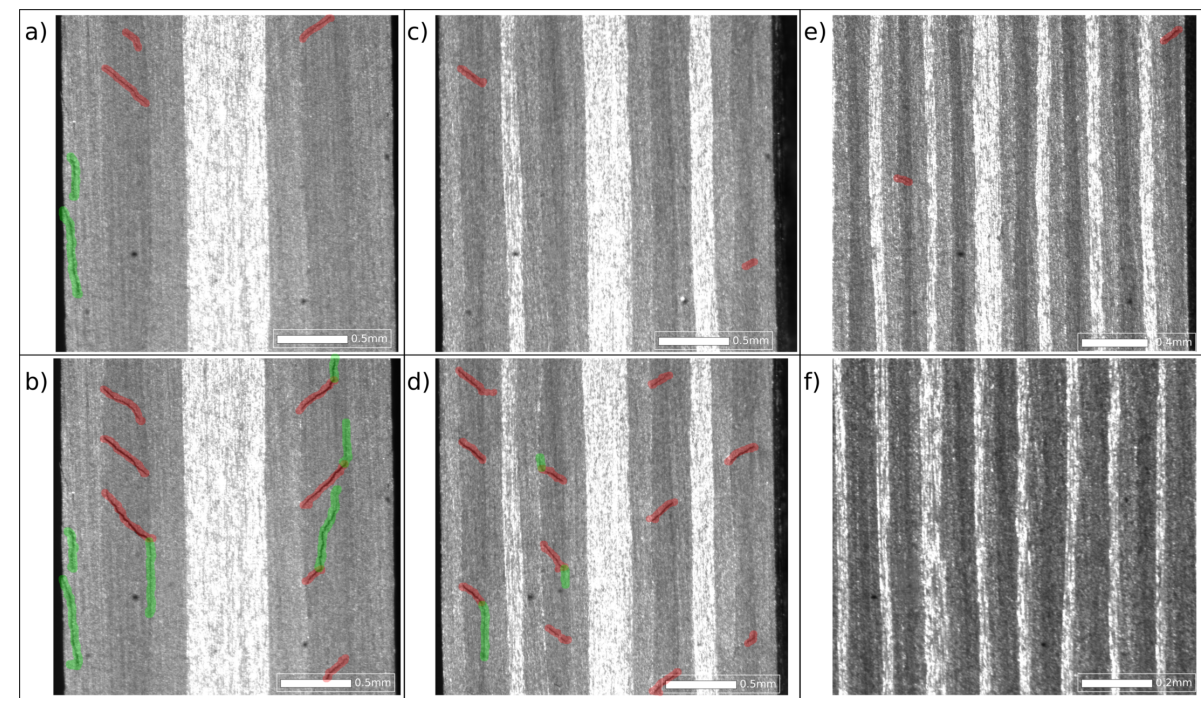

Figure 9: Optical in-situ micrographies showing the damage development at the free edges of chosen specimens. Transverse cracking is highlighted in red and matrix cracking induced delamination in green. $\mathrm{t}=300 \mu \mathrm{m}$ at $0.31 \%$ strain in (a) and $0.55 \%$ in (b), $\mathrm{t}=150 \mu \mathrm{m}$ at $0.5 \%$ strain in (c) and $0.85 \%$ strain in (d), $\mathrm{t}=75 \mu \mathrm{m}$ at $0.9 \%$ strain in (e) and $\mathrm{t}=30 \mu \mathrm{m}$ at $1.05 \%$ strain in (f) 
a)

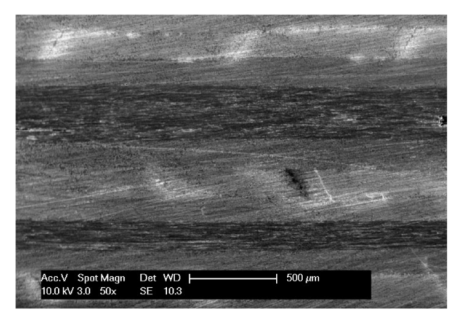

b)

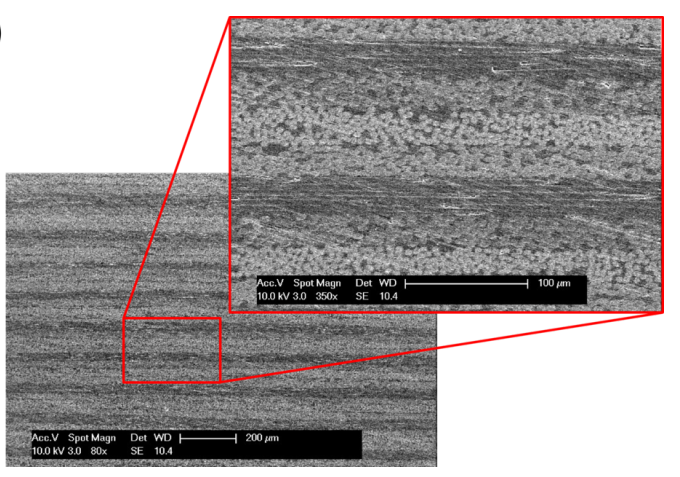

FIGURE 10: SEM visualisation of the polished edge of broken samples. a) for $150 \mu \mathrm{m}$ plies, with clear signs of transverse cracking, and b) for $30 \mu \mathrm{m}$ plies, with no visible damage in the $90^{\circ}$ plies. If tell-tale signs of transverse cracking are extremely visible in (a), they are totally absent in (b) 


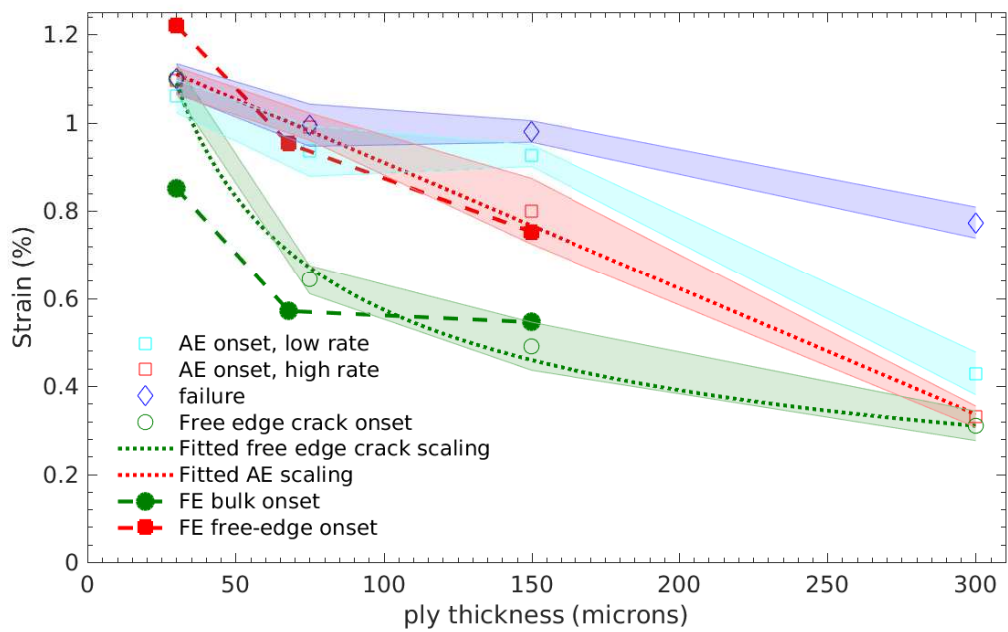

Figure 11: Macro-Scale Results, showing the good agreement of the free edge cracks to a $1 / \sqrt{t}$ scaling, whereas the onset of damage defined by an acoustic emission threshold is in better agreement with a linear scaling, and lightly loading-rate dependant. The corresponding numerical results are shown in dashed line, showing the good agreement with experimental results 
a)

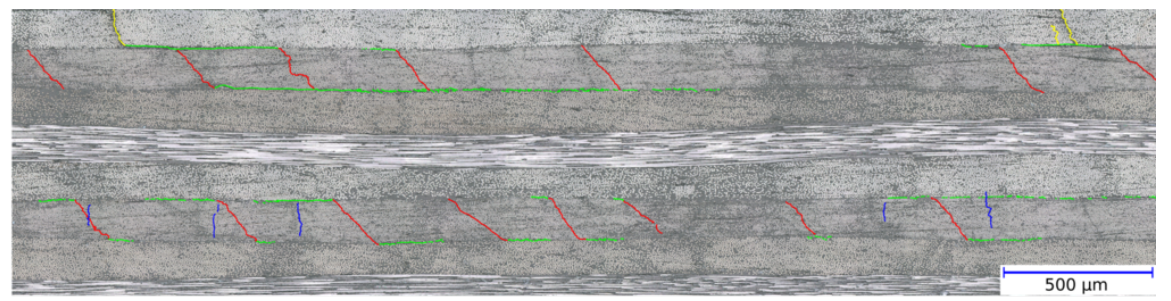

b)

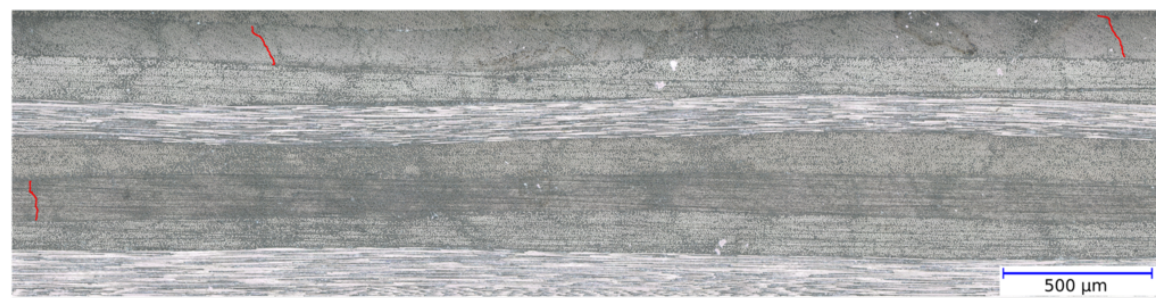

C)

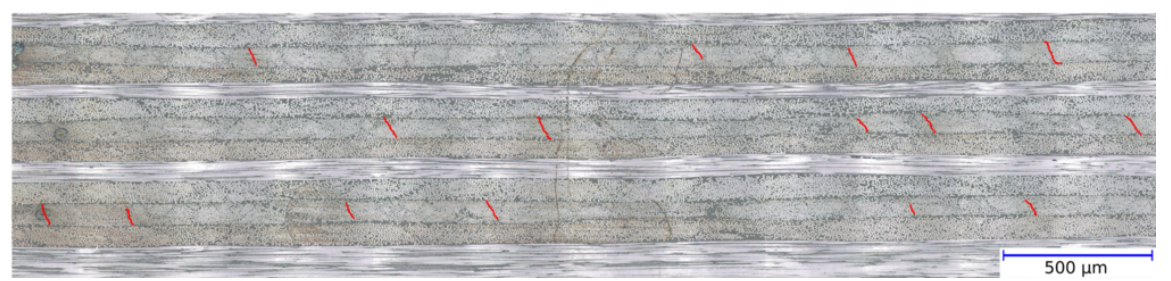

FiguRe 12: Free edge micrographs of the partially loaded specimens, manufactured with $150 \mathrm{\mu m}$ plies and loaded until $0.89 \%$ strain in (a), manufactured with $150 \mathrm{\mu m}$ plies and loaded until $0.64 \%$ strain in (b), and manufactured with $75 \mu \mathrm{m}$ plies and loaded until $0.89 \%$ strain in (c). Transverse cracks at the free edge are highlighted in red, the same damage type reaching the middle of the sample in blue, delamination in green and secondary damage in yellow 
a)
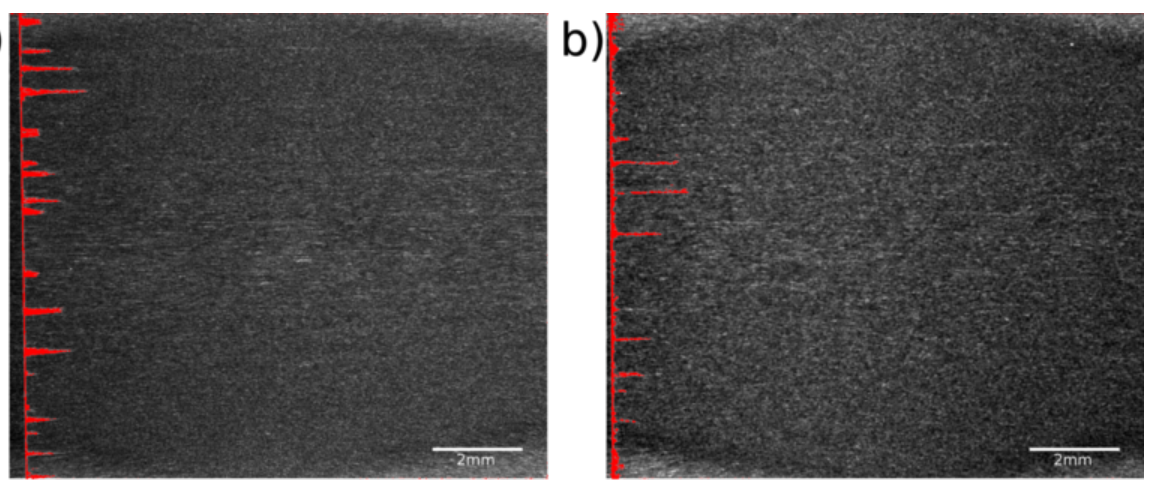

c)
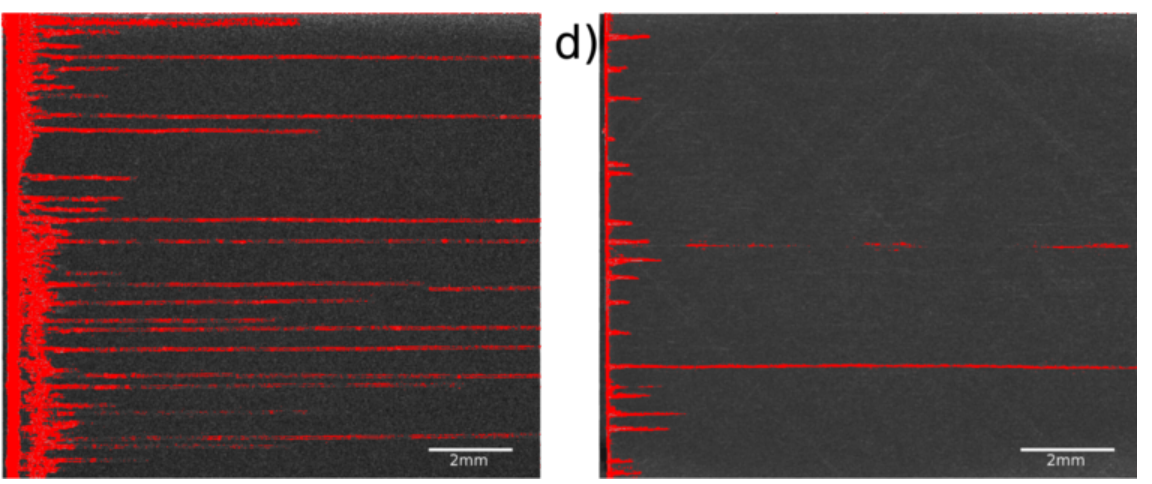

Figure 13: Typical $90^{\circ}$ plies : a) $\mathrm{t}=150 \mu \mathrm{m}$ loaded until $0.64 \%$ strain, b) $\mathrm{t}=100 \mu \mathrm{m}$ loaded until $0.83 \%$ strain, c) $\mathrm{t}=150 \mu \mathrm{m}$ loaded until $0.89 \%$ strain, d) $\mathrm{t}=100 \mu \mathrm{m}$ loaded until $0.89 \%$ strain. Transverse cracking clearly propagates into the bulk of the samples past AE onset. 


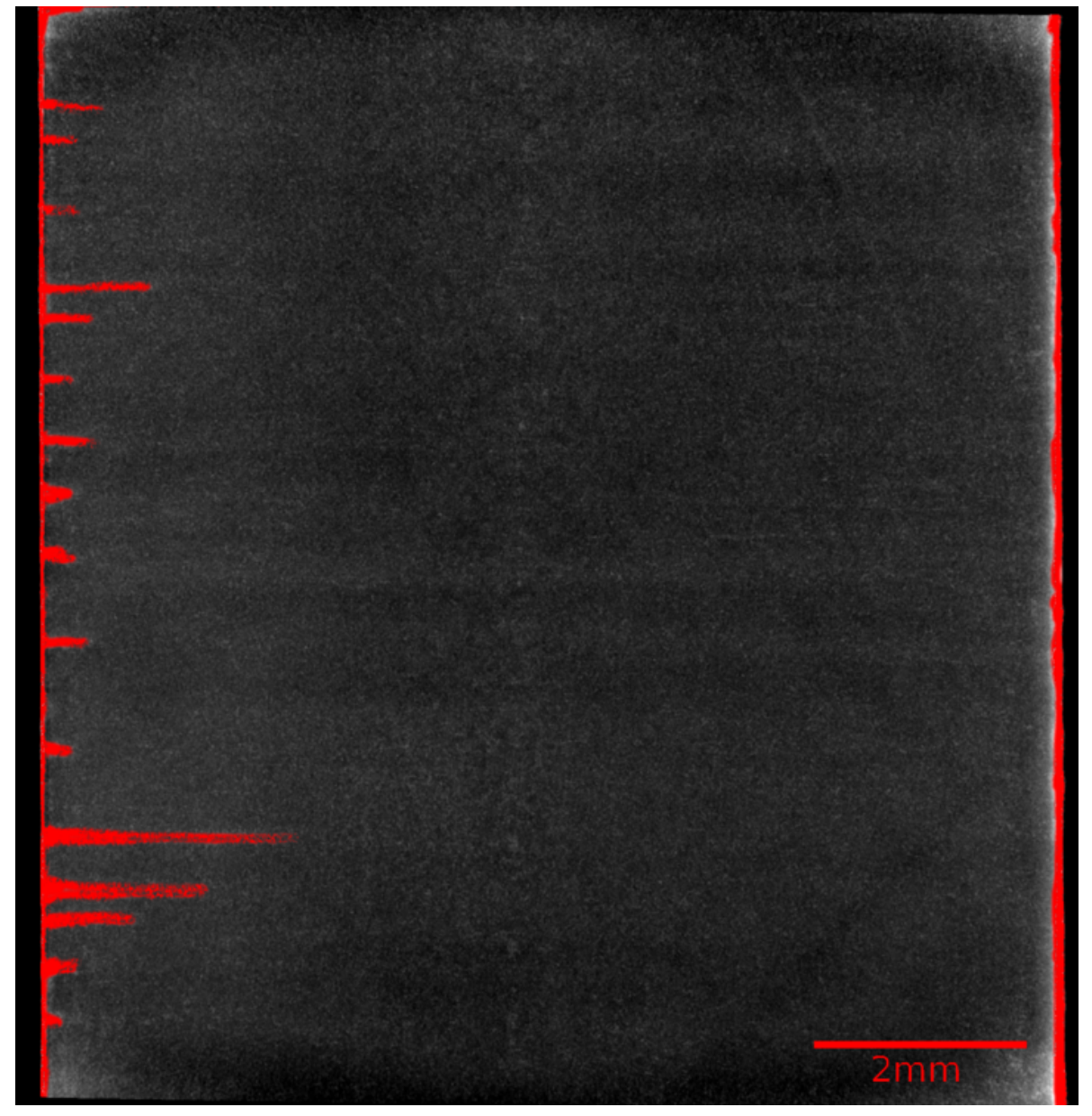

FIgURE 14: Typical $90^{\circ}$ ply of the machined sample, revealing no evidence of damage originating from the center of the specimens 


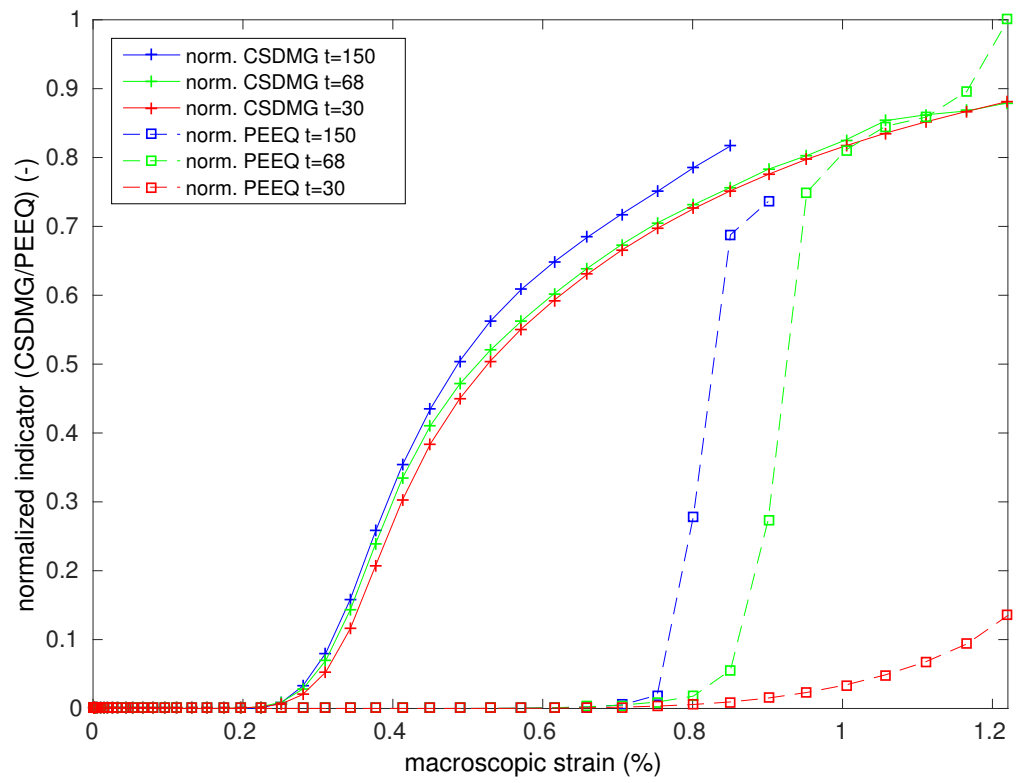

FIGURE 15: Average interfacial (cohesive) damage indicator CSDMG and equivalent plastic strain PEEQ for the three ply thicknesses, normalised by the maximum value reached for all ply thicknesses. Clearly, the decrease of ply thickness delays damage localisation. 


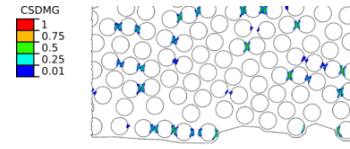

$0.28 \%$ strain

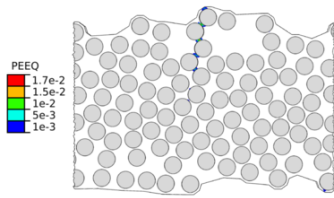

$0.80 \%$ strain

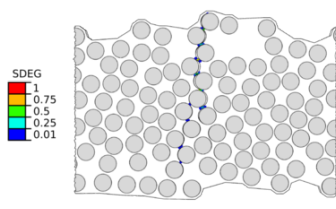

$0.90 \%$ strain

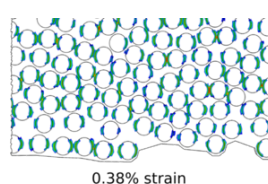
$0.38 \%$ strain

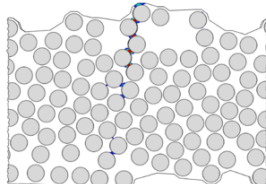

$0.85 \%$ strain

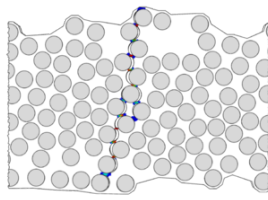

$0.95 \%$ strain
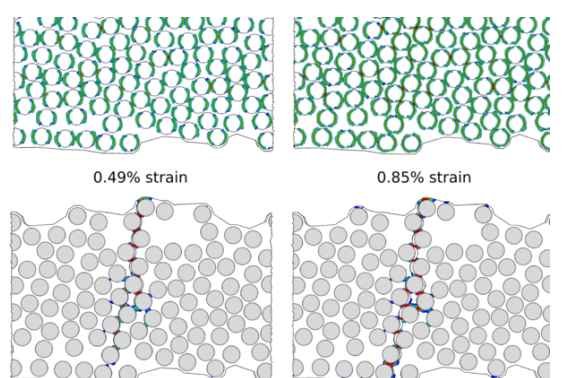

$0.90 \%$ strain

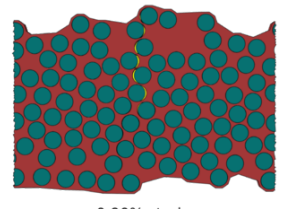

$0.90 \%$ strain

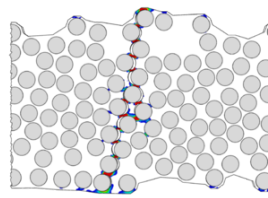

$0.95 \%$ strain

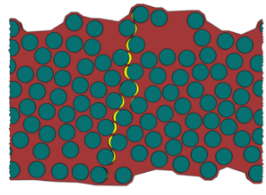

$0.95 \%$ strain

Figure 16: Damage evolution of a typical crack in the $68 \mu \mathrm{m}$ model. The typical damage process starting by progressive debonding (CSDMG damage variable) followed by plastic straining of the matrix ligaments represented by their equivalent plastic strain (PEEQ) leading to their eventual damage (SDEG damage variable) is highlighted. The two figures at the lower right corner highlight the progressive crack opening, with the opening voids shown in yellow. 

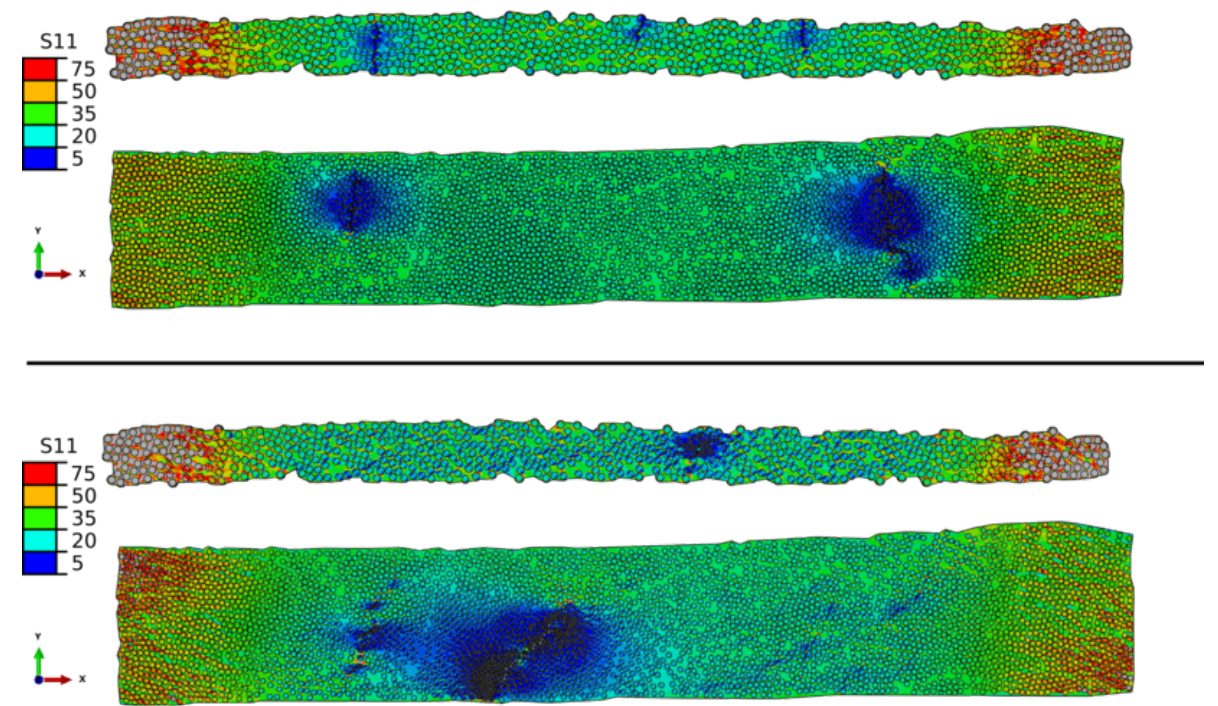

FiguRE $17: \sigma_{11}$ at $1.3 \%$ applied strain for the $30 \mu \mathrm{m}$ model and $0.82 \%$ for the $150 \mu \mathrm{m}$ model in the bulk and at $0.85 \%$ for the $30 \mu \mathrm{m}$ respectively $0.53 \%$ for the $150 \mu \mathrm{m}$ at the free edge. The crack propagation lasts for a few time steps of the simulation and the present illustrations represent the state at which the onset of damage was defined. 


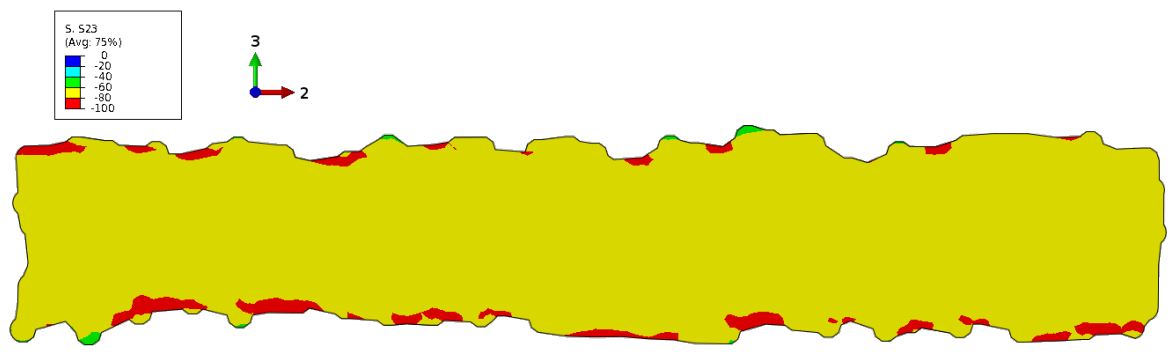

Figure 18: $\tau_{23}$ stress at the free edge of the $\mathrm{t}=68 \mu \mathrm{m}$ M40JB-TP80ep model, explaining the angle of the transverse cracks observed both experimentally and numerically at the free edge 


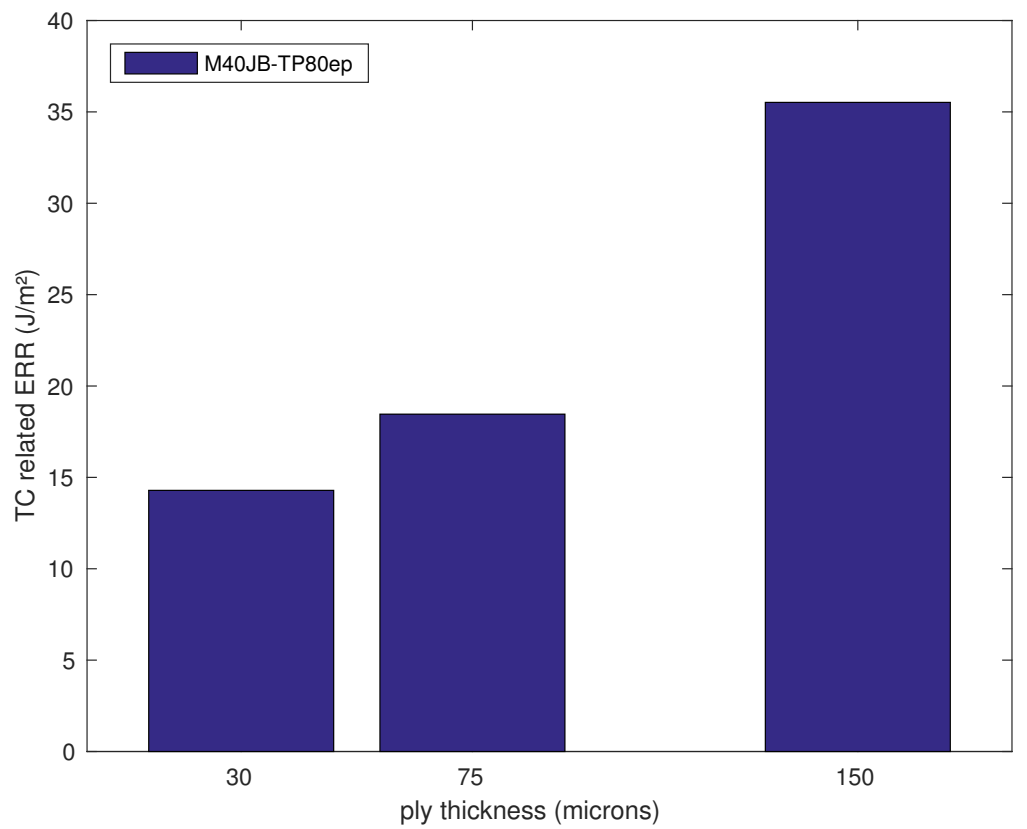

FIGURE 19: Critical transverse cracking related ERR obtained from the bulk numerical model. 